\title{
Electrospinning: processing technique for tissue engineering scaffolding
}

\author{
A. Martins ${ }^{* 1,2}$, R. L. Reis ${ }^{1,2}$ and N. M. Neves ${ }^{1,2}$
}

Electrospinning has attracted tremendous interest in the research community as a simple and versatile technique to produce synthetic polymeric ultrafine fibres with diameters ranging from a few micrometres to tens of nanometres. Recently, some natural origin polymers have also been successfully electrospun. Owing to their very small diameter, polymeric nanofibres exhibit unusual properties such as high specific surface area, flexibility in surface functionalities and superior mechanical properties. In addition, electrospun non-woven meshes could physically mimic the extracellular matrix structure of native tissues. These remarkable properties render electrospun nanofibres useful for many applications, particularly those related to the field of biomedical engineering. The first part of this review is intended to provide a fundamental survey of the electrospinning process (apparatus, governing parameters) and of recent improvements of the technique, including associated structural modifications of polymeric nanofibre meshes. The prospective tissue engineering/biomedical applications of electrospun polymeric nanofibres are then reviewed, namely, wound dressings, medical prostheses, drug delivery systems, DNA release and tissue engineering scaffolds. The essential properties of scaffolds in terms of the structural features of electrospun nanofibre meshes are discussed. Finally, the future perspectives for applications of electrospun nanofibres, particularly in the field of tissue engineering, are considered.

Keywords: Electrospinning process, Tissue engineering, Biodegradable scaffolds, Nanofibrous structures, Wound dressing, Medical prostheses, Drug delivery systems, DNA release systems

\section{Introduction}

Nanostructures and the nanotechnologies to produce them have been a subject of intensive research due to the unique properties that can be obtained and their potential applications in many areas. A large number of technologies have already been demonstrated as being able to generate nanostructures in the form of fibres, ${ }^{54,155}$ among them electrospinning. The electrospinning technique may be considered as a variation of the electrostatic spraying (or electrospraying) process, ${ }^{31}$ used in technologies such as time of flight secondary ion mass spectrometry ${ }^{175}$ and other spectrometric methods. ${ }^{18}$ In electrospraying, small droplets or particles are formed as a result of the varicose break-up of the electrified jet that is often present with a solution of low viscosity. ${ }^{41}$ In electrospinning, a solid fibre (composed of a viscous polymer solution) is produced by the generated electrical field. Subsequently, nanofibres are formed by continuous stretching, due to the electrostatic repulsion

\footnotetext{
13B's Research Group (Biomaterials, Biodegradables and Biomimetics), University of Minho, Campus de Gualtar, 4710-057 Braga, Portugal ${ }^{2}$ IBB (Institute for Biotechnology and Bioengineering), PT Government Associated Laboratory, Braga, Portugal

*Corresponding author, email amartins@dep.uminho.pt
}

between the charged nanofibres and the evaporation of the solvent. ${ }^{31}$

Although the term 'electrospinning', derived from 'electrostatic spinning', was proposed relatively recently (around 1994), its origin as a viable fibre spinning technique can be traced back to the mid 1930s. Formhals $^{37}$ patented, in 1934, his first invention, describing the process and the apparatus for producing artificial filaments using electrical charges. In 1964, Taylor ${ }^{167}$ developed fundamental studies on the jet formation process. The observed conical shape of the jet was later referred by other researchers as the 'Taylor cone'. In subsequent years, the focus shifted to studying the structural morphology of nanofibres owing to the development of atomic force microscopy (AFM), transmission electron microscopy (TEM) and even scanning electron microscopy (SEM) tools. Researchers were occupied with the structural characterisation of fibres and the understanding of the relationship between the structural features and process parameters. ${ }^{13,26,27,31,38,113,134,166,192}$ A major upsurge in electrospinning research took place due to the application potential of nanofibres in areas such as filtration systems, protective clothing, catalyst substrates, photonics, sensors and tissue engineering scaffolding. $29,54,87,102,163$ Strangely enough, although the 
electrospinning process has been known for more than 70 years, the mechanism by which nanofibres is formed is not fully understood. Although a number of studies have been carried out to investigate the mechanism of fibre formation in order reproducibly to control scaffold design, little theoretical understanding has been achieved.

According to the review by Huang et al. ${ }^{54}$ more than 100 different polymers have been successfully spun into ultrafine fibres using this technique (most dissolved in solvents yet some electrospun from melt) for various applications. The potential applications in cell biology and tissue engineering has resulted in a large number of biodegradable polymers being electrospun into nanofibres, including poly (caprolactone) (PCL) ${ }^{7,89,91,94,125,130,193}$ poly(lactic acid) ${ }^{72,191,197}$ (PLA), poly(glycolic acid) (PGA) ${ }^{15,16}$ and poly(lactideco-glycolide) (PLGA). ${ }^{90,100,139,186}$ In addition to these synthetic biodegradable polymers, natural biopolymers, such as DNA, ${ }^{34,134}$ silk fibroin, ${ }^{62,82,115,116}$ fibrinogen, ${ }^{111,183}$ dextran, ${ }^{59}$ collagen $^{109,110,149,202}$ and chito$\operatorname{san}^{42,126}$ have been successfully processed by electrospinning. Relative to synthetic polymers, natural origin polymers have good biocompatibility; conversely, their processability is, in general, poor.

A number of functional polymers envisaged for specific applications have been directly electrospun into nanofibres. However, many functional polymers are not suitable for use with electrospinning, because of their limited molecular weights and/or solubilities. One of the most effective strategies for solving this problem is to blend them with polymers that are well suited for electrospinning. ${ }^{87}$ This is a feasible approach that may not only reduce the potential problem of cytotoxicity, as a result of using a chemical cross-linking reagent, but also provides a well designed solution for overcoming the shortcomings of synthetic and natural polymers. Indeed, the production of new biomaterials with good biocompatibility and improved mechanical and physical/chemical properties has been achieved. ${ }^{52,60,117,199,201}$

Electrospinning is an attractive approach for polymer biomaterials processing, providing an opportunity to control morphology, porosity and composition using relatively unsophisticated equipment. Unlike conventional fibre spinning processes that produce fibres with diameters in the micrometre range, ${ }^{174}$ electrospinning is capable of producing fibres in the nanometre diameter range, which are typically deposited in the form of nonwoven fabrics. Nanofibres provide a connection between the nanoscale and the macroscale world, since although their diameters are in the nanometre range, they are very long entities, sometimes of the order of kilometres. ${ }^{134}$ Even the largest diameters produced by electrospinning are more than 10 times smaller than those that can be extruded to manufacture textile structures and woven mats.

When the diameters of polymer fibre materials are shrunk from the micrometre (e.g. $10-100 \mu \mathrm{m})$ to the submicrometre or nanometre scale (e.g. 10-100 nm), several interesting properties arise, such as very large surface area to volume ratio (which for a nanofibre can be 1000 times of that of a microfibre), flexibility in surface functionalities and superior mechanical performance (e.g. stiffness and tensile strength) compared with any other known form of the material. ${ }^{54}$ It is known that the natural extracellular matrix (ECM) of various tissues is composed of randomly oriented collagen fibres with nanometre scale diameters. Indeed, the architecture of the electrospun nanofibrous structure is dimensionally, but not morphologically, similar to those of some natural ECMs. ${ }^{102,155}$ The non-woven mats produced have the additional advantages of controllable pore size, high porosity with interconnected pores and permeability. ${ }^{68,193}$ These outstanding properties make the polymer nanofibres effective candidates for many important applications, particularly for tissue engineering/biomedical applications.

The present review is organised into three main sections. First, the fundamentals of the electrospinning process are considered; this survey includes an overview of the electrospinning apparatus and the parameters governing the process (the effects of these processing parameters have been reviewed in detail previously). ${ }^{1,138}$ Recent developments of the electrospinning process enabling production of different nanofibrous structures (e.g. core/sheath combinations, hollow, porous or aligned nanofibres) are also reviewed (some of these nanofibre structures have been reviewed previously). ${ }^{48,121}$

The following section provides an extensive discussion of the potential tissue engineering/biomedical applications of electrospun nanofibres, such as wound dressing, medical prostheses, drug delivery systems, DNA release and tissue scaffolding, with a focus on the electrospun polymer structures and biological evidence. This approach is intended to capture the state of the art of understanding for each type of biomedical application and is the distinctive feature of the present review: a critical assessment of electrospinning as a technique to produce tissue engineered scaffolds. While similar information has been presented in other reviews, $5,9,92,108,123,129,170,200$ these articles have not covered these tissue engineering/biomedical applications in comparable depth.

The next section reviews scaffold target properties and the extent that these have been achieved by electrospinning nanofibres. The achievements to date and the deviations from the target properties are of utmost importance in identifying the process improvements required to obtain the tailored nanofibrous scaffolds needed for tissue engineering applications. The review concludes with a section covering future perspectives on applications and opportunities raised by the development of electrospinning, particularly in the field of tissue engineering.

\section{Electrospinning process}

Electrospinning involves applying a very high voltage to a capillary filled with the polymer solution to be spun. Mutual charge repulsion induced by the electrical field causes a force directly opposite to the surface tension of the polymer fluid. As the intensity of the electrical field is increased, the hemispherical surface of the fluid at the tip of the capillary tube elongates to form a conical shape, known as 'Taylor cone', observable in various spinning techniques. With increasing electrostatic field, a critical value is attained when the repulsive electrostatic force overcomes the surface tension of the polymer solution and a charged jet of fluid is ejected from the tip of the Taylor cone. ${ }^{31,134}$ 


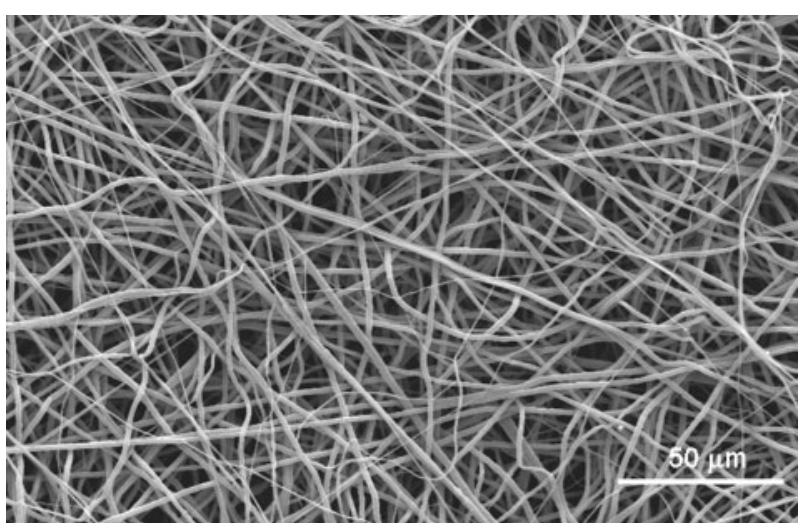

1 SEM images of polycaprolactone (PCL) nanofibres in mesh, produced by electrospinning

As the jet progresses from the capillary towards the collector, the forces from the external electrical field accelerate and stretch the jet. Stretching and evaporation of the solvent molecules cause the jet diameter to become smaller. As the radius of the jet becomes smaller, the radial forces from the charge can become large enough to overcome the cohesive forces of the fibre and cause it to split into two or more fibres, that is, to splay. This jet division process occurs several more times in rapid succession and produces a large number of small electrically charged fibres moving toward the collector. The divided jets repel each other, thereby acquiring lateral velocities and chaotic trajectories, which gives a brush like appearance in the region beyond the point at which the jet first splays. Splaying and elongation appear to occur simultaneously in many cases. ${ }^{134}$ However, recent observations of Yarin et al. ${ }^{192}$ suggest that the jet, while moving towards the collector, undergoes a chaotic motion or bending instability, due to the repulsive forces originating from the charged ions within the electrospinning jet. Because electrospinning is a continuous process, the fibres could be as long as several kilometres. In the electrospinning process, these long fibres can be assembled into a three-dimensional, non-woven mat as a result of bending instability of the spinning jet (Fig. 1).

\section{Electrospinning apparatus}

There are basically three components to complete a functional electrospinning set-up: a high voltage power supply, a spinneret constituted by a glass capillary tube or a needle of small diameter, and a grounded metal collecting screen (Fig. 2). The electrospinning apparatus is usually set up in a chemical hood to allow the exhaustion of organic vapours. In addition, a closed, non-conductive environment with temperature and humidity control is required to avoid interference from environmental factors, such as air turbulence. ${ }^{92}$ Several groups working on electrospinning have adopted different solutions for the polymer flow through the needle. ${ }^{14,73,104}$ Some have simply opted for placing the capillary perpendicularly, letting the polymer fluid drop under gravity and placing the collector underneath. ${ }^{73}$ Sometimes the capillary can be tilted at a defined angle to control the flowrate through the capillary. ${ }^{104}$ Other authors mount the capillary horizontally and a pump is used to initiate the droplet. The pump is also used in the case of vertical feeding. ${ }^{14}$ The electrode can be inserted

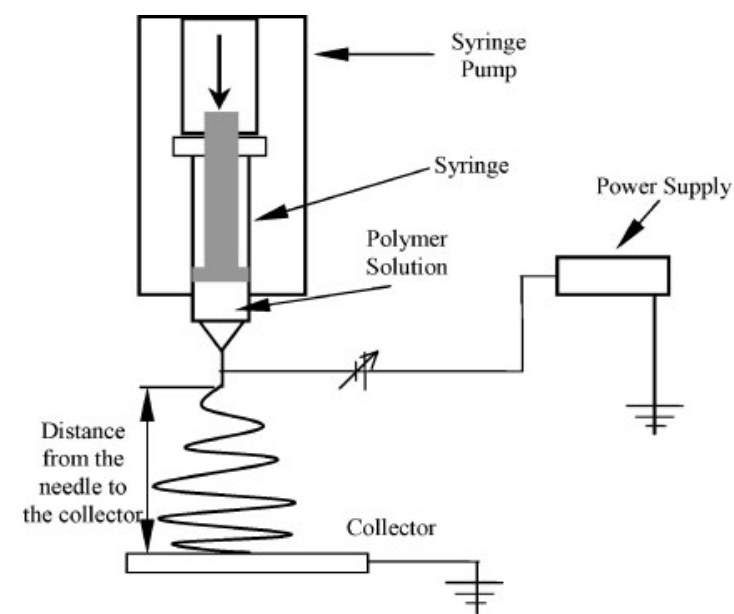

2 Schematic representation of electrospinning apparatus (adapted from Ref. 125)

either in the polymer fluid or placed onto the tip of the capillary if a syringe with a metal needle is used. ${ }^{38}$ The collector is usually a plane metal sheet or a grid that can be covered with a fabric, although rotating cylinders covered with a grounded aluminium sheet could also be used. $^{70}$

Most polymers commonly used in electrospinning are dissolved in appropriated solvents before being electrospun. ${ }^{31,54,134,163}$ Molten polymers can also be processed into nanofibres through electrospinning (usually at relatively high temperatures) ${ }^{101}$ the polymer melt is introduced direct into the capillary tube rather than the solution. However, electrospinning of a polymer melt must be performed in a vacuum condition.

\section{Governing parameters}

The foregoing discussion suggests that the following parameters significantly affect the electrospinning process:

(i) intrinsic solution properties: viscosity, elasticity, conductivity and surface tension ${ }^{13,26,31}$

(ii) operational conditions: hydrostatic pressure in the capillary tube, electrical potential at the capillary tip, capillary diameter and distance between tip and collecting screen ${ }^{38,125}$

(iii) ambient parameters such as solution temperature, humidity and air velocity in the electrospinning chamber. ${ }^{113,163}$

By appropriate tuning of one or more of these parameters, fibres may be successfully electrospun from water soluble polymers, biopolymers or liquid crystalline polymers.

Generally, the polymer solution must have a concentration high enough to have sufficient number of polymer entanglements yet not so high that the viscosity prevents the polymer flow induced by the pump and the stretching caused by the electrical field. The solution must also have a surface tension low enough, a charge density high enough and a viscosity high enough to prevent the jet from coalescing into droplets before the solvent has evaporated. ${ }^{31}$ In the electrospinning process, the properties of the solvent, such as volatility and polarity (dielectric constant), have a significant influence on the morphology and diameter of the electrospun fibres. The electrospinning of a polymer in a polar solvent generally produces ultrathin fibres with smaller 


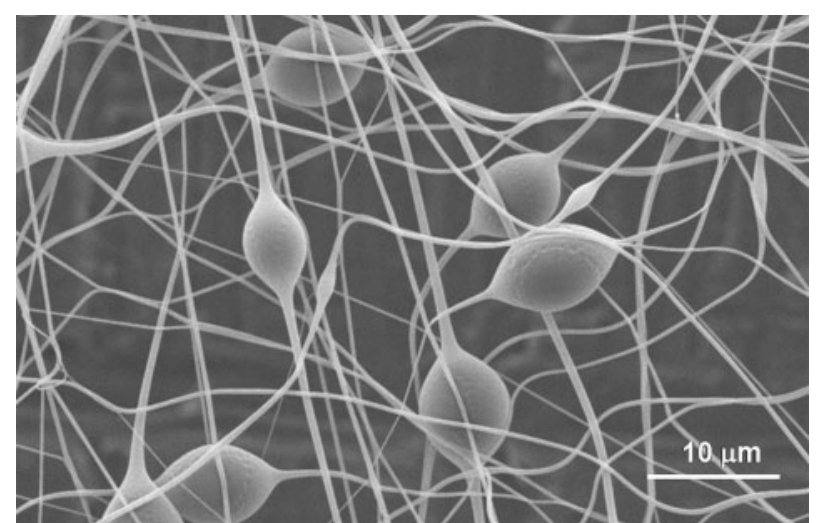

3 SEM image of polyvinylpyrrolidone (PVP) nanofibres with beads in its structure

average diameters, although the effect of solvent polarity on the fibre diameters has not been systematically studied. ${ }^{13}$ Morphological changes can occur upon decreasing the distance between the spinneret and the collector. Increasing the distance or decreasing the electrical field decreases the probability of beads in the mesh, regardless of the concentration of the polymer in solution. ${ }^{38}$

As long as a polymer can be electrospun into nanofibres, ideal targets would be:

(i) that fibre diameters be uniform, consistent and controllable

(ii) that the fibre surface be defect free

(iii) that continuous single nanofibres be collectable. However, to date, these three targets have proved by no means easily achievable. As long as no splitting is involved, one of the most significant parameters influencing fibre diameter is solution viscosity: high viscosity results in a larger fibre diameter. In general, fibre diameter tends to decrease with increasing electrospinning voltage, although the influence is not as strong as that of the polymer concentration. An additional challenge is to control the uniformity of fibre diameters with current electrospinning equipment. ${ }^{26,27,31,113}$ The base of the Taylor cone when formed is equal to the orifice diameter of the needle. Therefore, it was hypothesised that a change in the base of the Taylor cone will potentially influence the forces necessary for its formation, the formation of the jet and thus the diameter of the nanofibres. As predicted, a decrease in the base of the Taylor cone (orifice diameter) caused a decrease in the average diameter of the nanofibres formed. ${ }^{54}$

The structure and morphology of electrospun fibres is also affected by the spinneret tip to collector distance because of their dependence on the deposition time, evaporation rate and whipping or instability regions. Shorter spinneret tip collector distances tend to produce wetter fibres and beaded structures. Thus, aqueous polymer solutions require longer distances to dry fibre formation than systems that use highly volatile organic solvents. The flowrate of the polymer at the syringe is another important process parameter, since it influences jet velocity and material transfer rate. Therefore, the fibre diameters and the pore size are larger when the polymer flowrate is higher. Increased flowrate also increases the tendency to form beaded morphologies. ${ }^{113}$ Indeed, a common problem encountered in electrospinning is the formation of structure defects, such as beads and pores caused by local excess of solvent, which may occur in polymer nanofibres (Fig. 3). ${ }^{51}$ The beads may form as a result of an instability in jet initiation, which is correlated with properties of the polymer solution (viscosity and surface tension) as well as there being insufficient force to stretch the polymer jet. This effect may be due to the electrical field or to the boundary conditions such as spinneret tip diameter. In other words, it is more likely to be possible to electrospin bead free fibres from thicker spinneret tips with higher polymer concentration solution. Fibre diameter could be significantly decreased by decreasing polymer concentration, although there is a limit to obtain uniform nanofibres without beads. Furthermore, adding filler material into a polymer solution can also result in fibres free from beads. ${ }^{54}$

\section{Recent developments on electrospinning process}

Electrospinning apparatus is simple in construction and there have been no significant developments in the equipment design in the past decade. Some research groups $7,33,86,125,194,199,202$ have improvised the basic electrospinning set-up to suit their experimental needs in terms of materials and applications. In improve control of the electrospinning process and thus, tailor the structures of resultant fibres, the set-up (in particular, the collector and the spinneret) has also been modified. In general, electrospinning is a process with limited productivity because the polymer solution has to be fed at relatively slow rates (usually less than $1 \mathrm{~mL} \mathrm{~h}^{-1}$ ), to obtain ultrathin fibres. Productivity enhancement for commercialising products obtained by electrospinning is under active research, with emphasis on multiple spinneret designs, and alternative experimental set-ups have recently been demonstrated. ${ }^{33}$ However, there is still debate on the potential of scaling up this technology for commercialisation. From the available published literature and the current state of understanding of the electrospinning process, it is likely that commercial scaling-up of the electrospinning process will be achieved only when a more fundamental understanding of the process and better control of the instability behaviour of the jets is achieved.

The conventional set-up for electrospinning involves the use of a single capillary as the spinneret and thus is suitable only for generating fibres with one particular composition in each run of fabrication, exhibiting a solid interior and a smooth surface. Recent demonstrations established that nanofibres with some specific secondary structures (e.g. core/sheath or hollow, and porous) could also be prepared if appropriated processing parameters (e.g. electrical field strength, concentration of solution and feedrate of solution) or new designs of spinnerets were employed. With the use of the conventional electrospinning set-up, it is possible to fabricate core/ sheath nanofibres from a polymer solution containing two polymers that will phase separate as the solvent is evaporated. Core/sheath or hollow nanofibres could also be fabricated by coelectrospinning of two different polymeric solutions through a spinneret comprising two coaxial capillaries ${ }^{53,61,83,86,97,199}$ (Fig. 4). It has thus amply been demonstrated that electrospinning is capable of fabricating nanostructures with complex 


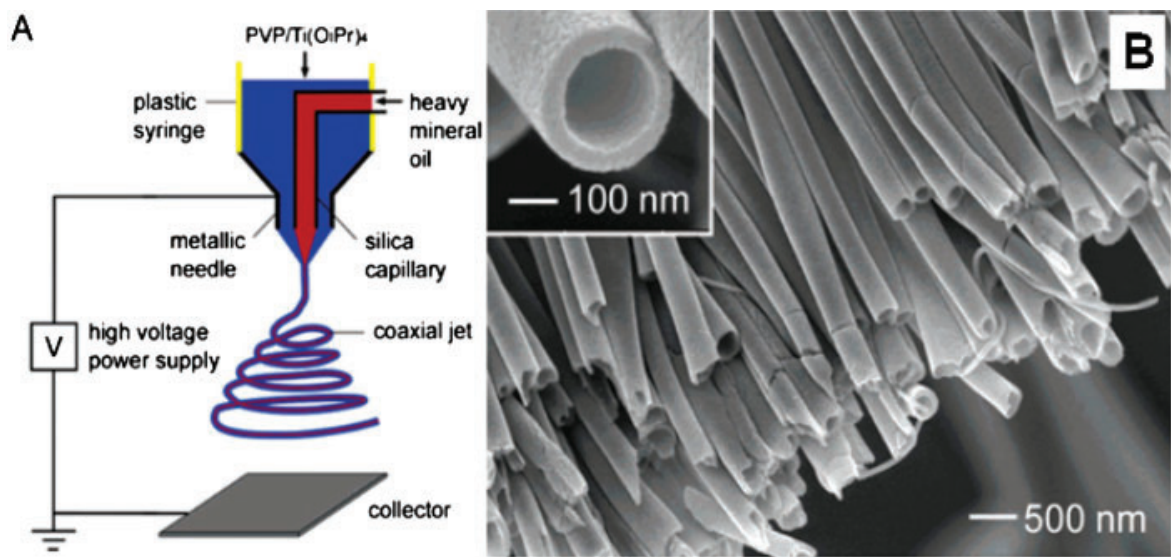

4 A schematic illustration of set-up for electrospinning nanofibres having core/sheath structure: system is based in spinneret with two coaxial capillaries, and $B$ SEM image of uniaxially aligned array of $\mathrm{TiO}_{2}$ hollow fibres after both mineral oil extraction from core and calcinations (adapted from Ref. 86: ๑2004 ACS)

functionalities. It is also speculated that it will be possible to fabricate hollow nanofibres with multiple walls using a spinneret composed of more than two coaxial capillaries. ${ }^{87}$

The specific surface area of a nanofibre can be greatly increased when its structure is switched from solid to porous. ${ }^{97}$ Increase in surface areas is beneficial to many applications that include catalysis, filtration, absorption, fuel cells, solar cells, batteries or tissue engineering. Two slightly different approaches have been reported to introduce a porous structure into the bulk of an electrospun nanofibre. One is based on the selective removal of one component used to produce nanofibres made from a two phase material, such as a composite or a blend. The other involves the use of phase separation technology during electrospinning with appropriate spinning parameters ${ }^{13}$ (Fig. 5).

Most nanofibres obtained to date are in the nonwoven form, which can be useful for a small number of applications such as filtration, tissue engineering scaffolds, implant coating film, and wound dressing. However, by analogy with the traditional fibre and textile industry, only when continuous single nanofibres or uniaxial fibre bundles are obtained will their range of applications be expanded. This is a very tough target to

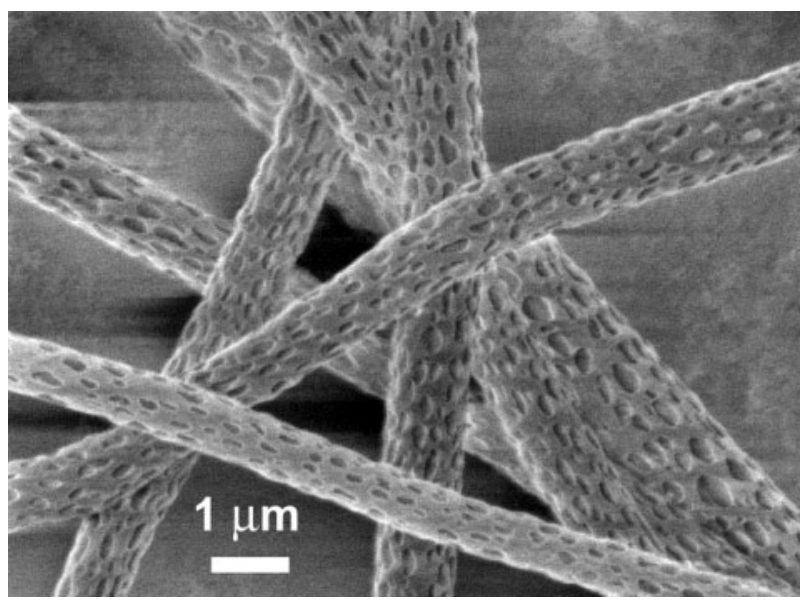

5 SEM images of PLLA fibres with pores at surface obtained via electrospinning of solution of PLLA in dichloromethane (from Ref. 13: @2001 Wiley-VCH Verlag) achieve with electrospun nanofibres, because the polymer jet trajectory is a complex three-dimensional 'whipping' path, caused by bending instability, rather than a straight line. To date, no continuous long fibre yarn has been reported and the publications related to aligned nanofibres are very limited. ${ }^{54}$ It has been suggested that by rotating a cylinder collector at a very high speed (up to thousands of revolutions per minute), electrospun nanofibres could be oriented circumferentially (e.g. PGA and type I collagen). ${ }^{70}$ However, fibre alignment was achieved only to some extent. The reason why a perfect alignment is difficult to achieve can be attributed to the fact that the chaotic motions of polymer jets are not likely to be coherent and are not controllable. Even so, a large amount of work has been carried out in the field of nanofibre alignment, regarding the use of rotating systems as collectors in the electrospinning process. ${ }^{7,80,91,124,165,169,187,190}$ A significant advance in collecting aligned electrospun nanofibres has been made by Theron et al. ${ }^{171}$ who described a novel approach to position and align individual nanofibres on a tapered and grounded wheel like bobbin. The tip like edge substantially concentrates the electrical field so that the as spun nanofibres are almost all attracted to and continuously wound onto the bobbin edge of the rotating wheel.

Investigation is continuing to understand the alignment characteristics in terms of varying the shape and size of frame rods, the distance between the frame rods, and the inclination angle of a single frame. ${ }^{54}$ Fong et al. ${ }^{36}$ obtained aligned nylon 6 fibres by rapidly oscillating a grounded frame within the electrospun polymer jets. In another approach, it was demonstrated that using a multiple field technique, the polymer jet, usually in chaotic oscillating motion as it approaches the collection target, can be straightened to some extent. ${ }^{27} \mathrm{Li}$ et al. ${ }^{84}$ recently demonstrated that the geometrical configuration of a conductive collector had a profound effect on the orientation of electrospun nanofibres (Fig. 6). Using a collector consisting of two conductive strips separated by a gap of variable width (up to several centimetres), electrospun fibres could be uniaxially aligned over long lengths during the spinning process. ${ }^{28,85,146}$ This collecting process has been termed the 'gap method of alignment', and it results in single electrospun fibres, oriented and suspended between two collection plates. 
A
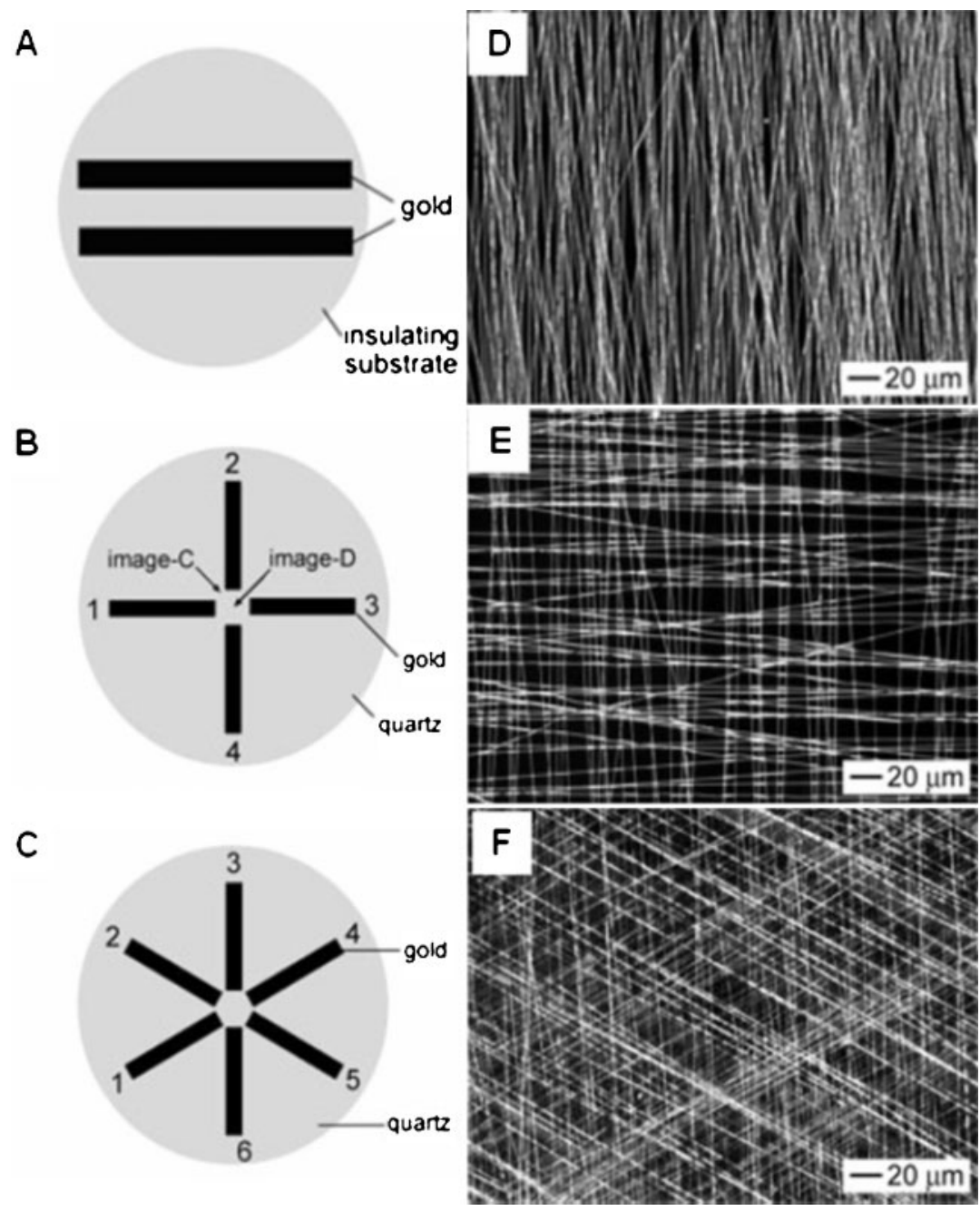

6 A-C schematic illustration of collectors based in gold electrodes deposited over insulating substrates and $D-F$ dark field optical micrographs of PVP nanofibres collected between electrodes $A-C$ respectively (adapted from Ref. 85: ๑2004 Wiley-VCH Verlag)

In a different strategy, copper wires spaced evenly in the form of a circular drum as a collector resulted in sheets with $1 \mathrm{~cm}$ wide strips of aligned nanofibres. ${ }^{64}$ In a recent paper, Teo and Ramakrishna ${ }^{170}$ described a simple method of obtaining a fibre bundle of micrometre scale diameter from nanofibres aligned between two parallel steel blades with a gap between them. A similar structure composed of aligned nanofibres, developed by Dalton and colleagues, ${ }^{25}$ was obtained using two grounded collection rings or circular discs equidistant from the spinneret, by rotating one of the collection rings.

It may also be possible to integrate electrospinning with conventional lithographic techniques to obtain new fabrication platforms for generating patterned microstructures from a variety of materials and a broad range of length scales. Czaplewski et al. ${ }^{24}$ deposited nanofibres of poly(methyl methacrylate) as templates for the formation of functional nanomechanical devices (e.g. nanomechanical oscillators), combined with lithographically defined support structures. Afterwards, Liu and collaborators ${ }^{96}$ developed sensor devices that utilized individual oriented polymeric nanowires of polyaniline/ poly(ethylene oxide) deposited on lithographically defined microelectrodes.

\section{Tissue engineering/biomedical applications of electrospun nanofibres}

From a biological perspective, almost all human tissues and organs are deposited in some kind of nanofibrous form or structure. ${ }^{155}$ Examples include, among many others, bone, collagen, cartilage and skin. ${ }^{2,148,195}$ All of these are characterised by well organised hierarchical fibrous structures realigning on a nanometre scale. ${ }^{160}$ As such, current research in electrospun polymer nanofibres has focused extensively on biomedical products. Tissue engineering has been recognized, for some time, as a promising alternative to the use of autografts or allografts for tissue reconstruction and regeneration. $^{44,45,77}$ This approach utilises cells, biomaterial scaffolds and signalling molecules for the repair of diseased or damaged tissues. However, other applications are also envisaged, such as wound dressings and prostheses.

\section{Wound dressing}

An ideal dressing will cover and protect a wound, providing an environment at the surface of the wound in which healing can take place at the maximum rate, with good dermosthetic appearance. ${ }^{200}$ Modern dressings are 


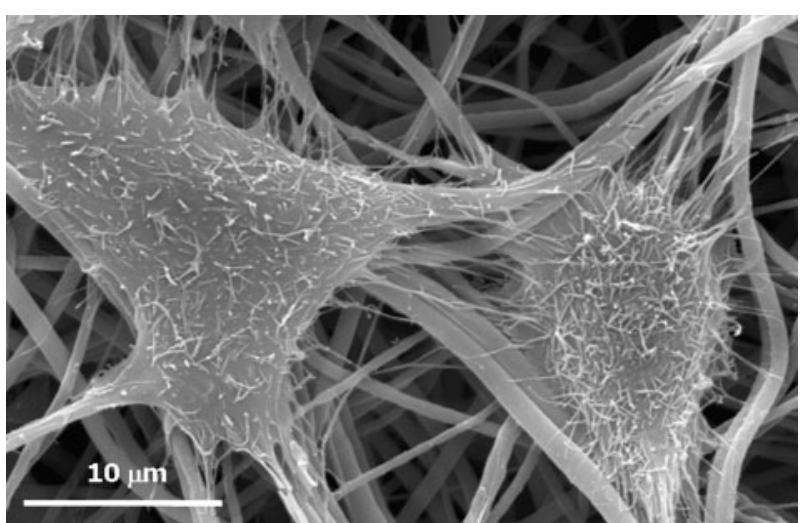

7 Mouse lung fibroblasts (L929 cell line) adhered on plasma modified PCL nanofibre meshes

developed to serve the purpose of facilitating wound healing apart from the basic function of covering wounds and protecting them from infections. It has been noted by several authors ${ }^{79,183,200}$ that an ideal dressings is required to:

(i) be haemostatic

(ii) be efficient as a bacterial barrier

(iii) absorb excess exudates

(iv) provide and maintain a moist environment or appropriate water vapour transmission rate, and provide adequate gaseous exchange

(v) conform to the limits of the wound area

(vi) adhere to healthy tissue but not to wound tissue, i.e. to show functional adhesion

(vii) be painless to the patient and easy to remove

(viii) provide these qualities at an affordable cost.

Current efforts using polymer nanofibrous membranes as medical dressings are still at an early stage (Fig. 7). Fibrinogen is a soluble protein that is present in the blood plasma and has been shown to play a key role in wound healing. Human and bovine fibrinogen nanofibre mats have been electrospun and developed for their potential use as a tissue engineered scaffold, wound dressing or haemostatic bandage. ${ }^{69,79,183}$ Electrospun poly(ethylene-co-vinyl alcohol) membranes also appear to be favourable substrates for tissue engineering, wound coverage and healing; one has been shown to support the culturing of aortic smooth muscle cells and dermal fibroblasts. ${ }^{67}$ Recently, cytocompatibility and cell behaviour of primary normal human keratinocytes (NHK) and fibroblasts cultured on silk fibroin (SF) nanofibrous membranes were also reported. ${ }^{115,116}$ The adhesion of cultured cell types was evaluated using type I collagen, fibronectin or laminin as substrates, which were adsorbed onto the SF nanofibres. The results indicated that type I collagen, one of the integrin ligands, is functionally active in terms of cell adhesion onto the electrospun SF nanofibres for both keratinocytes and fibroblasts tested. In another study, the same research group produced a nanofibrous matrix of type I collagen from calfskin via electrospinning. ${ }^{135}$ In cell activity assessment, electrospun collagen nanofibres coated with type I collagen or laminin were found to promote cell adhesion and spreading of NHK. Additionally, the effect of collagen nanofibres on open wound healing in rats and athymic mice ${ }^{133}$ was very effective as wound healing accelerators in early stage wound healing. In those studies, SF and type I collagen nanofibre non-wovens produced by electrospinning were introduced for wound dressing and scaffolds for tissue engineering. The performance of electrospun nanofibrous polyurethane (PU) membranes as dressings was examined in vivo using a pig model. ${ }^{69}$ To validate the application in the medical field, morphological properties of the membranes were characterised and wound healing was investigated. This wound dressing showed controlled evaporative water loss, excellent oxygen permeability and promoted fluid drainage owing to the presence of porous nanofibres and the inherent properties of PU. Histological examination confirmed that epithelialisation rate was increased and the exudate in the dermis was well controlled by covering the wound with the electrospun membrane.

\section{Medical prostheses}

Polymer nanofibres fabricated via electrospinning have been proposed for a number of soft tissue prostheses applications, such as arterial blood vessel ${ }^{50,159}$ and breast. ${ }^{132}$ Electrospun biocompatible polymer nanofibres can also be deposited as a thin porous film onto a hard tissue prosthetic device designed to be implanted into the human body. ${ }^{19}$

The search for vascular grafts substitutes has been a half century endeavour. Although polytetrafluoroethylene $\mathrm{e}^{180}$ and polyethylene terephthalate (PET) (Dacron) ${ }^{182}$ have been successful in treating the pathology of large diameter arteries ( $>6 \mathrm{~mm}$, inner diameter), no materials have been successful in replacing small diameter blood vessels $(<6 \mathrm{~mm})$. The first approach using the electrospinning technique to obtain biomimetic vascular graft scaffolds was developed by Stitzel and colleagues. ${ }^{162}$ The graft was fabricated with collagen fibres wound on a stainless mandrel and covered with electrospun PLA. The vascular construct was seeded with human aortic smooth muscle cells (SMCs) and general cellular orientation along the principal stress lines was observed. In a recent article, Venugopal et al. ${ }^{177}$ reported the development of biocomposite nanofibre scaffolds of PCL and collagen types I and III. In vitro studies with coronary artery SMCs revealed that these biocomposites constitute promising scaffolds for the regeneration of smooth muscle tissue for blood vessel engineering.

In recent years, creating a biodegradable polymer scaffold with an endothelialised surface has become an attractive concept for replacement of small diameter blood vessels. Taking this into account, $\mathrm{Xu}$ et al. ${ }^{189}$ cultured human vascular endothelial cells (ECs) on electrospun and solvent cast poly(L-lactic acid) (PLLA) substrates with different surface roughness and showed that EC function was enhanced on the smooth solvent cast surface relative to the rough electrospun surface of PLLA nanofibres. Interestingly, in previous work, ${ }^{118,188}$ the same research group demonstrated that a nanofibre matrix of the block copolymer of poly(L-lactic acid)-copoly( $\varepsilon$-caprolactone), P(LLA-CL), could support the adhesion and proliferation of ECs and SMCs. This synthetic nanofibre matrix combined the advantages of synthetic biodegradable polymers with the biocompatible mimicking architecture of extracellular matrix, to have great potential for blood vessel engineering. To facilitate viability, attachment and phenotypic maintenance of human coronary artery ECs, an electrospun collagen coated P(LLA-CL) nanofibre mesh was 


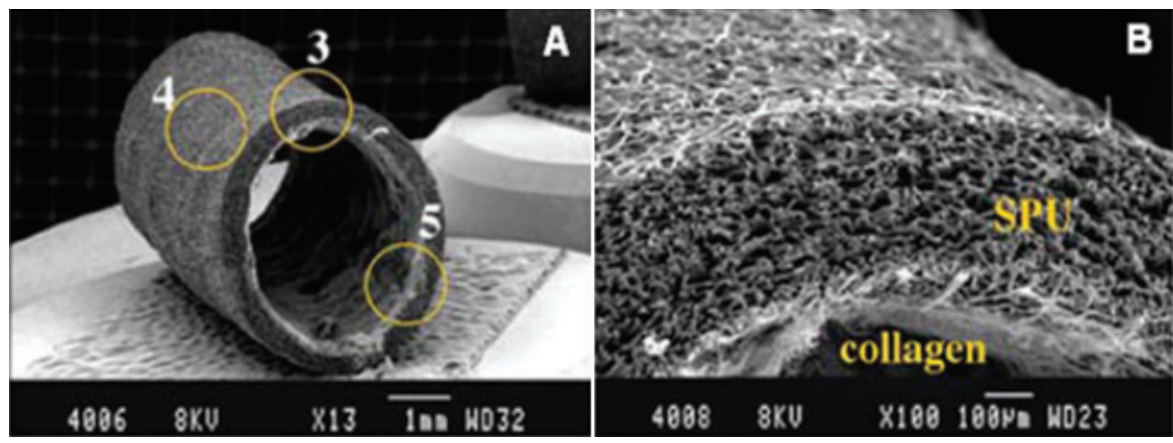

A SEM image of tube; $B$ magnified image of region 3 in micrograph (from Ref. 75: $\odot 2005$ Elsevier

8 Fabricated bilayered tubular construct composed of polyurethane tube with interior surface coated with collagen

fabricated through plasma treatment followed by collagen coating. ${ }^{49}$ The collagen coated nanofibrous structure also showed mechanical properties suitable for tissue engineered vascular grafts (Fig. 8). A similar study was recently presented by Jeong et al., ${ }^{58}$ demonstrating the effectiveness of a dynamic culture on the engineering of vascular grafts. Additionally, for prosthetic vascular grafts, directional bias of fibres with respect to the tubular axis is required to mimetically obtain anisotropic vascular grafts so as to improve burst strength. Aligned P(LLA-CL) nanofibrous scaffold have been successfully produced. ${ }^{187}$ Cell culture results of SMCs on the nanofibrous scaffold indicated that cells adhered and migrated along the direction of aligned nanofibres, showing a significant improvement over polymer films.

Vascular graft scaffolds have also recently been fabricated using electrospun polymer blends of type I collagen from calf skin $(45 \%)$, elastin from ligamentum nuchae $(15 \%)$ and PLGA $(40 \%) .{ }^{161}$ The biocompatibility of the scaffolds was tested with bovine ECs and SMCs and assessed by MTT metabolic assay and neutral red assays. The biocompatibility of the electrospun vascular scaffolds was also tested in vivo. Favourable interactions between SMCs and ECs on the scaffold were demonstrated by cellular morphology, histology and immunostaining. Ma et al. ${ }^{103}$ processed a conventional polymer used in vascular grafts, PET, into non-woven nanofibre mat via electrospinning. To overcome the chemical and biological inertness of the PET surface, gelatin was covalently grafted onto the PET nanofibrous surface. Endothelial cells were cultured on the original and gelatin modified PET nanofibre meshes and results demonstrated an improvement of spreading and proliferation of the ECs, maintaining their phenotype. Altogether, these studies demonstrate the potential of electrospinning as a method to fabricate functional vascular grafts for clinical applications, using different biomaterials.

\section{Drug delivery systems}

The ability to influence the fibre diameter, by changing the polymer solution concentration and/or its surface tension, and the ability to incorporate therapeutic compounds into the mats during spinning afford the prospect of preparing useful polymer systems for controlled drug delivery. Moreover, two potential advantages of the electrospinning approach are the avoidance of melt processing, which is especially important for heat sensitive drugs, and minimisation of the initial burst. The nature of the polymer can direct the use of the electrospun fibres with water soluble polymers giving rise to immediate release dosage forms and water insoluble (i.e. biodegradable or non-biodegradable) polymers, being useful for sustained release systems. Thus, the fabrics generated with water soluble carriers could be used in oral dosage formulations by direct incorporation of the materials into a capsule or by further processing (i.e. milling of the fabrics). ${ }^{178}$ Covalent conjugation of drugs to polymers represents an alternative strategy for moderating the rates of drug release. This strategy, however, requires the presence of side chains/functional groups, which are generally only abundant in some hydrophilic biodegradable polymers. Unfortunately, the electrospun membranes prepared from hydrophilic polymers generally have poor mechanical strength, especially in their swollen state, and also tend to disintegrate faster in vivo. Moreover, chemical cross-linking is generally needed to solidify and stabilise the electrospun membranes prepared from hydrophilic polymers, and most of those chemical reactions have potential toxicity. In addition, hydrophilic and water soluble polymers tend to leach out rapidly from the blends when incubated in an aqueous environment. Thus, it is necessary to find hydrophilic polymers that are soluble in organic solvents and insoluble in water under physiological conditions, for preparing composite electrospun membranes. ${ }^{60}$

Drug delivery devices including polymer nanofibres are based on the principle that dissolution rate of a drug may be mediated by the surface area of both the drug and the corresponding carrier. Since drugs and carrier materials can be mixed together to produce nanofibres by electrospinning, various interaction modes in the resulting nanostructured products can be envisaged:

(i) the drug as tiny particles attached to the surface of the nanofibre carriers

(ii) both drugs and carriers are in nanofibre form, resulting in an interlaced structure

(iii) a blend of drugs and carrier materials integrated into a single type of composite nanofibre

(iv) the carrier material is electrospun into a tubular form in which the drug particles are encapsulated.

Modes (i) and (ii) tend to give rise to a problem of burst release in the initial stages of incubation and therefore, modes (iii) and (iv) may be preferred. ${ }^{54}$

Kenawy et $a l^{66}$ were the first to describe the incorporation of a drug into polymeric nanofibres. They found that electrospun poly(ethylene-co-vinylacetate) (PEVA) released $65 \%$ of its drug (tetracycline hydrochloride) content within $120 \mathrm{~h}$, whereas the $50: 50$ 
material (PEVA/PLA) released $\sim 50 \%$ over the same time period. Mats of PLA fibres exhibited some instantaneous release, most probably caused by tetracycline hydrochloride on the fibre surfaces. In addition, the percentage of tetracycline released after 5 days from electrospun PEVA was only about twice that released from Actisite (tetracycline periodontal fibres). In general, the total percentage release from the cast films was lower than that from the electrospun mats, as would be expected due to the much lower surface area of the former. In other work, bioabsorbable nanofibre membranes of PLA were used for loading an antibiotic drug, Mefoxin (cefoxitin). ${ }^{205}$

For potential use in topical drug administration and wound healing, poorly water soluble drugs loaded in water soluble and water insoluble nanofibrous polymer carriers were investigated. ${ }^{178,179}$ Verreck et al. ${ }^{179}$ reported that solvent casting and melt extrusion of hydroxypropylmethylcellulose results in samples that rapidly release itraconazole, with the solvent cast film giving more complete release. Samples produced using electrostatic spinning resulted in a complete in vitro release over time, but the dissolution rate was slower than for either the cast thin films or the melt extruded, milled powder. Additionally, it was shown that drug loaded polymer electrospun nanofibres were able to disperse drugs in an amorphous state, which facilitates drug dissolution.

Zeng and co-workers ${ }^{198}$ described a perfect inclusion of Rifampin and Paclitaxel inside PLLA fibres, in that no burst release of drug was observed. These drugs are lipophilic and highly soluble in PLLA/chloroform/ acetone solution. When the solution jet was rapidly elongated and the solvent evaporated quickly, the drug remained compatible with PLLA. Doxorubicin hydrochloride (a hydrophilic drug) was also used in this study and limited solubility in the electrospinning solution was reported. During the rapid evaporation of the solvent, phase separation took place quickly between the drug and PLLA. Therefore, the solubility and compatibility of the drug in the drug-polymer-solvent system was a decisive factor.

Electrospun nanofibrous meshes can also be used as carriers for hydrophilic drugs, where the drug release profile can be finely controlled by the modulation of scaffold morphology, porosity and composition. By taking advantage of the unique solubility characteristics of poly(ethylene glycol)-g-chitosan (PEG-g-CHN), Jiang and colleagues ${ }^{60}$ prepared by electrospinning a highly porous composite membrane composed of PLGA and PEG-g-CHN, without the need for cross-linking. These membranes are mechanically robust and flexible, and have high porosity, hydrophilicity and capacity to sustained release of ibuprofen, rendering them suitable for direct application to atrial tissue. Kim and coworkers $^{71}$ successfully incorporated a hydrophilic antibiotic drug, Mefoxin (cefoxitin sodium), into electrospun PLGA and PLGA/PLA/PEG-b-PLA $(80: 5: 15)$ nanofibres, without the loss of structure and bioactivity. It was demonstrated that the introduction of an amphiphilic PEG-B-PLA block copolymer in the polymer matrix reduced the cumulative amount of the release at earlier time points and prolonged drug release rate to 1 week. In addition, the released cefoxitin sodium from electrospun scaffolds was found to be structurally intact as well as effective in Staphylococcus aureus growth inhibition, in both static and dynamic environments.

The use of electrospun fibres as drug carriers will be also promising in future biomedical applications, especially post-operative local chemotherapy. Along those lines, Katti et al. ${ }^{65}$ reported the development of a novel bioresorbable, polymeric nanofibre based antibiotic delivery system for the treatment of wounds; Cefazolin was incorporated into PLGA nanofibres using the free acid form of the antibiotic. Zong et al. ${ }^{204}$ examined the effect of using electrospun non-woven bioabsorbable PLGA impregnated with antibiotics (Mefoxin) as an anti-adhesion membrane based on an in vivo rat model. These delivery systems would potentially have two functions: as a topical/local antibiotic delivery system and as a resorbable/biodegradable gauze whose degradation products are easily metabolised by the body. A particular advantage of this delivery system would be the possibility of delivering uniform and highly controlled doses of bioactive agents at the wound site via the high surface area to volume ratio of the nanofibre system. Another advance in postoperative localised drug administration focused on vascular grafts. Sustained delivery of heparin to the localised adventitial surface of the grafted blood vessels has been shown to prevent vascular smooth muscle cell (VSMC) proliferation leading to graft occlusion and failure. Luong-Van et al. ${ }^{98}$ successfully incorporated heparin into electrospun PCL fibre mats. The effect of heparin incorporation on the fibre morphology was studied, as well as heparin dispersion and release rates. A homogeneous distribution of heparin was found throughout the fibre mats and continuous diffusional release over 14 days. In addition, the fibres did not elicit a proinflammatory response, as assessed through in vitro macrophage assay, and the released heparin was effective in preventing the proliferation of VSMCs in culture.

A number of authors $59,65,66,71,98,179,198,204,205$ have successfully encapsulated drugs into electrospun fibres by mixing the drugs in the polymer solution to be electrospun. Fewer, however, have encapsulated proteins in electrospun polymer fibres..$^{20,143,196}$ Proteins such as growth factors are often the most important biochemical signalling agents for tissue engineering applications. A recent study developed by Chew et al. ${ }^{20}$ demonstrated the feasibility of encapsulating human nerve growth factor (NGF) by electrospinning it into a biodegradable fibre composed of the copolymers poly(e-caprolactone) and ethyl ethylene phosphate (PCLEEP). Partially aligned protein encapsulated fibres were obtained and the protein was found to be randomly dispersed throughout the electrospun fibrous mesh in aggregate form. A sustained release of NGF from electrospun fibrous mesh for up to 3 months was observed. Additionally, it was confirmed that the NGF released at the end of this time period was, at least partially, bioactive in stimulating PC12 cells differentiation into neurons. In another study, Zeng et al. ${ }^{196}$ reported the release of comparable large proteins from electrospun poly(vinyl alcohol) (PVA) nanofibres obtained by electrospinning. The release of fluorescin isothiocyanate labelled bovine serum albumin or luciferase from electrospun PVA nanofibres was demonstrated; 
the burst release was retarded significantly by a postelectrospinning coating of highly hydrophilic poly(pxylylene). The preservation of enzyme activity and the continuous release of the intact enzyme from the immersed fibres meet a fundamental prerequisite for the application of enzymes or other sensitive agents released from electrospun nanofibres under physiological conditions.

\section{DNA release}

Fibres produced by electrospinning form a large, interconnected porous network that is ideal for drug, gene, as well as cell delivery. Fang and Reneker ${ }^{34}$ have previously reported on electrospinning of DNA fibres, utilising purified genomic DNA (calf thymus Na-DNA) as the polymer. Luu et al. ${ }^{100}$ utilised the unique capabilities of electrospinning to develop a biologically active scaffold for gene delivery. This study appears to be the first report describing the successful dispersion of plasmid DNA into polymeric solutions of PLA-PEG and PLGA, generating biologically active composite scaffold via electrospinning. Preliminary data indicate that, by manipulating the scaffold's properties (fibre diameter, porosity or pore size), it should be possible to accurately control the release of DNA from the scaffold, and thus decrease the rate of release at earlier times and sustain a more linear release for longer time periods. Additionally, these results indicated that the DNA released from the scaffold was not only intact, but also capable of cellular transfection. In a subsequent study, the same group ${ }^{95}$ developed a novel core-sheath DNA nanoparticle composed of condensed plasmid DNA in a triblock copolymer of poly(lactide)-b-poly(ethylene glycol)-b-poly(lactide). The mixture of encapsulated DNA and PLGA was then electrospun to form a non-woven nanofibrous and nanocomposite scaffold. This structure was capable of controlled release bioactive plasmid DNA in an intact form and transfect preosteoblastic MC3T3 cells in culture. Together, these results demonstrated that by understanding and using the molecular interactions of block copolymers and plasmid DNA in solution, novel structures and additional functionality can emerge. A deep understanding on the molecular selfassemblies and the electrospinning process has enabled the development of an effective gene delivery vehicle.

\section{Tissue templates/scaffolds}

A biodegradable scaffold is commonly recognised as an indispensable element in engineering living tissues. Scaffolds are used as temporary templates for cell seeding, proliferation and differentiation, to lead to the regeneration of the tissue. ${ }^{1,44,45,77}$ The design of biomaterial scaffolds for tissue engineering is an attempt to obtain functional replacement of the ECM, to support the desired cellular differentiation and maintain phenotype specific activities. Nanofibrous materials, by virtue of their morphological similarities to natural ECM, have been considered as promising scaffolds for tissue engineering applications. The difficulties with these structures include poor control of porosity and limited mechanical properties.

Diverse tissues that undergo injury could benefit from the potentialities of the nanofibrous structures produced by electrospinning. For instance, in cartilage regeneration, induction and maintenance of chondrocyte differentiation are obtained by embedding cells in agarose, or alginate, or in the form of a high density pellet. However, such cultures lack the mechanical stability provided by PCL nanofibrous scaffold, as described by Li et al. ${ }^{89}$ In subsequent work, ${ }^{94}$ it was demonstrated that electrospun nanofibres of PCL effectively support transforming growth factor $\beta 1$ induced chondrogenesis of adult human mesenchymal stem cells (hMSCs). The level of differentiation appeared to be equivalent to that observed in high density pellet cultures of hMSCs. In addition, nanofibrous scaffolds allowed cells to be grown on the same surface throughout their entire course of differentiation and maturation. The same group, in another study, ${ }^{93}$ showed that PCL nanofibrous scaffolds not only support the maintenance of a chondrogenic phenotype, but also provide a suitable scaffold for the osteogenic, chondrogenic and adipogenic differentiation of hMSCs. In a recent study, Subramanian et al. ${ }^{164}$ have evaluated a novel electrospun chitosan/polyethylene oxide (PEO) mat composed of oriented submicron fibres for its tensile properties and biocompatibility with canine chondrocytes (cell attachment, viability and proliferation). The results demonstrated that the electrospun aligned fibres had a higher modulus than anisotropic cast films, and provided good chondrocyte biocompatibility. A similar biological study, ${ }^{11}$ with chitosan/PEO nanofibres deposited as a non-woven membrane or as a highly aligned bundle, was developed with human chondrocytes (HTB-94 cell line) and osteoblasts (MG-63 cell line). Experimental results showed that the nanofibrous structure promoted adhesion and maintained characteristic cell morphology and viability throughout the period of study, properties of particular interest in tissue engineering for controlled drug release and tissue remodelling. In other recent work, ${ }^{3}$ starch based nanofibre meshes were presented as support structures for bovine articular chondrocytes proliferation and maturation, as demonstrated by the formation of extracellular matrix (glycosaminoglycans quantification) and immunoexpression of collagen types I and II.

Interesting work by Yoshimoto et al. ${ }^{193}$ demonstrated that electrospun PCL nanofibres are capable of supporting attachment and proliferation of rat bone marrow derived MSCs, which maintain their phenotypic shape and differentiation into osteoblastic cells under dynamic culture conditions. Shin et al. ${ }^{152}$ implanted MSC-PCL constructs subcutaneously in rats and showed new bone formation at the implantation site. These results were later confirmed by Boudriot and colleagues, ${ }^{17}$ who demonstrated osteogenic differentiation of hMSCs on a three-dimensional matrix of electrospun PLLA nanofibres. Therefore, nanofibrous structures processed by electrospinning could also be promising scaffolds for bone tissue engineering. Recently, Zhang et al. ${ }^{201}$ coelectrospun gelatin with PCL to produce composite fibrous scaffolds, which exhibited improved mechanical properties (namely, elongation and deformation), as well as more favorable wettability, than nanofibres obtained from either gelatin or PCL alone. Additionally, cell culture experiments with bone marrow stromal cells (BMSCs) showed favourable interactions (i.e. attachment and spreading) and cellular migration into the fibrous structure of this artificial polymeric material. In a recent study, guided bone regeneration (GBR) composite nanofibre membranes were successfully 


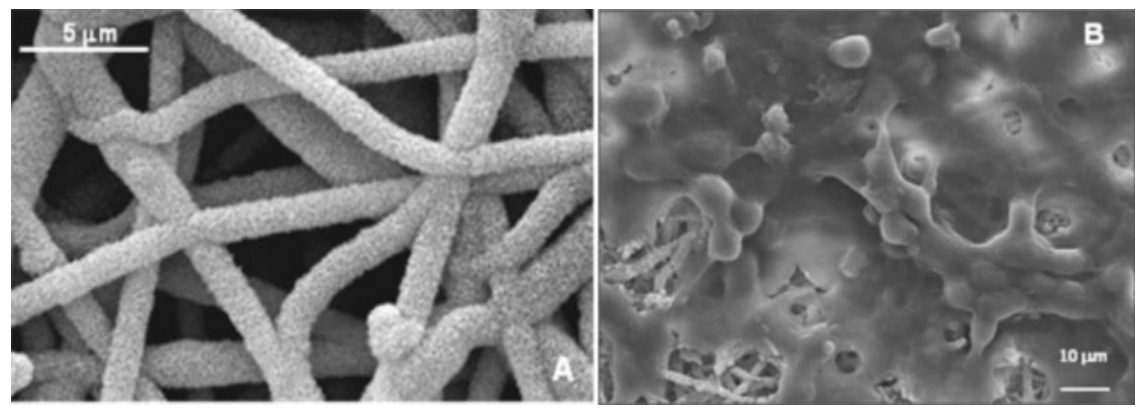

9 SEM images of $\boldsymbol{A}$ micrografts of electrospun poly( $\varepsilon$-caprolactone) nanofibre meshes after biomimetic calcium phosphate coating, keeping porous morphology (from Ref. 108) and $B$ morphology of Saos-2 cells cultured for 14 days on PCL nanofibre meshes coated with biomimetic coating (from Ref. 4)

fabricated by electrospinning of PCL/calcium carbonate $\left(\mathrm{CaCO}_{3}\right) .{ }^{39}$ Human osteoblasts (hFOB1·19 cell line) were cultured on composite nanofibrous GBR membranes, and MTS assay and SEM observation revealed good cell attachment and proliferation. Another study ${ }^{185}$ had also evaluated the osteoblast attachment and proliferation on composites of PCL nanofibres containing nanoparticles hydroxyapatite (HA). Results demonstrated that cells seeded on PCL/HA fibrous scaffolds presented higher viability than the cells seeded on scaffolds containing PCL/CaCO 3 or PCL alone. That behavior was attributed to the ability of HA to promote bone cell activities. Recently, the formation of an apatite layer has been induced over electrospun PCL nanofibre meshes, without the occurrence of pore occlusion. ${ }^{4}$ The biological influence of this biomimetic coating on osteoblatic like cells was assessed. It was shown that PCL nanofibre meshes coated with an apatite layer support and enhance the proliferation of osteoblasts for long culture periods (Fig. 9).

Nair and colleagues ${ }^{122}$ recently produced non-woven nanofibre meshes from poly[bis(p-methylphenoxy)phosphazene] (PNmPh) by electrospinning. This biodegradable polymer is a polyphosphazene, a class of inorganicorganic polymers known for their high biocompatibility, high temperature stability and low temperature flexibility. Furthermore, the electrospun nanofibre mats were studied to evaluate the biological performance. It was found that these mats supported the adhesion of bovine coronary artery endothelial cells, as well as promoting adhesion and proliferation of osteoblastic like MC3T3-E1 cells (mouse immortalised calvarial cells). This study indicated that the $\mathrm{PNmPh}$ nanofibre matrices could promote cell matrix and cell-cell interactions, making them potential candidates for various biomedical applications.

Many researchers ${ }^{62,82,112,115,116}$ have investigated silk proteins, mainly SF, as candidate materials for biomedical applications, because it has several distinctive properties including good biocompatibility, good oxygen and water vapour permeability, biodegradability and minimal inflammatory reaction. Jin et al. ${ }^{62}$ reported the ability of electrospun silk matrices to support human BMSCs attachment, spreading and growth in vitro, suggesting the potential use of these biomaterial matrices as scaffolds for tissue engineering. Electrospun silk fibroin mats were comparable with other biodegradable electrospun mats using PGA, ${ }^{15,116}$ PLGA, 90,100,139,186 collagen, ${ }^{109,110,202}$ collagen/PEO blends $^{52}$ that were tested for use as scaffolds for tissue regeneration. In fact, smooth muscle cells were observed to infiltrate an electrospun collagen (calfskin) nanofibre matrix and were well integrated into the network within 7 days of culture. ${ }^{110}$ Matthews ${ }^{109}$ also performed an in vitro study with chondrocytes, where it was also demonstrated that electrospun collagen type II scaffolds support cell proliferation and are readily infiltrated. More recently, a comparative study of collagen, gelatin (denaturated collagen), solubilised alpha-elastin and recombinant human tropoeslatin as biopolymeric materials for fabricating tissue engineering scaffolds by electrospinning was developed by $\mathrm{Li}$ and colleagues. ${ }^{88}$ In contrast to collagen and gelatin, which could be spun into fibres in the nanometre scale, the diameter of alphaelastin and tropoelastin fibres was always in the range of microns. The characterisation of the mechanical tensile moduli of electrospun fibres was also reported. Cell culture studies confirmed that these electrospun engineered protein scaffolds support attachment and growth of human embryonic palatal mesenchymal cells.

Numerous topographical and chemical strategies have been undertaken to create micro- and nanoscale enhanced features to regulate cell morphology and function. $^{35,160,181}$ In fact, very little was previously known about the textural effects of the fibrous matrix on tissue engineering. Park et al. ${ }^{115}$ studied the cytocompatibility and human oral keratinocytes behaviour on the different textures of SF (woven matrix of microfibres, films and non-woven matrix of nanofibres). Their results indicated that the SF nanofibre matrix promotes cell adhesion and spreading, using type I collagen as substrate, better than SF film and SF microfibre matrices. In subsequent work, ${ }^{117}$ they demonstrated that a PLGA/chitin composite non-woven matrix can be a better candidate than the PLGA nonwoven matrix in terms of cell adhesion and spreading for normal human keratinocytes, and that the PLGA and PLGA/chitin matrices are good matrices for normal human fibroblasts. These nanofibrous matrices showed promise for biomedical applications, such as wound dressing and scaffolds for tissue engineering. In a different topographical approach, nano- to microstructure biodegradable poly(L-lactide-co- $\varepsilon$-caprolactone) fabrics were prepared by electrospinning. ${ }^{74}$ Physical characterisation revealed that a decrease in the fibre diameter of the fabric resulted in a decrease in the porosity and on the pore size. This was followed by an increase in fibre density and mechanical strength. Biological assays demonstrated that human umbilical vein endothelial cells (HUVECs) were well adhered and 
proliferated on the small diameter fibre fabrics $(0 \cdot 3-$ $1.2 \mu \mathrm{m}$ in diameter), whereas markedly reduced cell adhesion, restricted cell spreading and no signs of proliferation were observed on the large diameter fibre fabric $(\sim 7 \cdot 0 \mu \mathrm{m}$ in diameter). The discussion suggests that electrospun elastomeric nanofibre fabric may be useful as temporary functional scaffolds in cardiovascular and muscular tissue engineering.

Nanofibrous structures were recently proposed as a potential cell carrier for neural tissue engineering by Yang et al. ${ }^{191}$ Production of PLLA nanofibrous scaffolds and the biological performance of neural stem cells (NSC) when seeded into those scaffolds was described. It was concluded that this nanostructure supports neural stem cell adhesion and enable NSCs differentiation and outgrowth of neurites. Later, the production of perfectly aligned PLLA fibrous scaffolds was achieved and in vitro studies demonstrated the elongation and neuritis outgrowth of NCS parallel to the direction of fibre alignment. ${ }^{190}$ Moreover, a comparative study with electrospun microfibres revealed a significant effect on the cell orientation. However, the NSC differentiation rate was higher for nanofibres than for microfibres.

Several studies on creating cardiac muscle cell constructs have also been reported. ${ }^{151,203}$ Studies that used a synthetic polymer scaffold typically concluded that the stiffness of the scaffold hindered tissue contractions. ${ }^{1,74}$ A study developed by Shin et al. ${ }^{151}$ introduced an in vitro system for engineered myocardium using a degradable, nanofibrous scaffold made of PCL by electrostatic fibre spinning. The cardiomyocytes penetrated the entire scaffold and stained positively for cardiotypical proteins, i.e. actin, tropomyosin and cardiac troponin-I. The work presented provides an alternative approach to engineered myocardium by relying on a synthetic polymer that provides sufficient stability and low opposition to contractions. In a similar approach, ${ }^{203}$ biodegradable polymer nanofibres of PLLA and PLGA (PLA10-GA90+PLLA and PLGA + PEG-PLA) were assessed for use in heart and cardiac tissue constructs. Primary rat cardiomyocytes (CMs) were cultured onto nanofibrous scaffolds and a dense multilayer of cells was obtained. It was also observed that CMs over electrospun PLLA scaffolds developed mature contractile structures (sarcomeres).

Skeletal muscle tissue engineering represents an attractive approach to overcome problems associated with autologous transfer of muscle tissue and provide a valid alternative for tissue replacement in the enhancement of muscle regeneration. In this context, Riboldi et al. ${ }^{136,137}$ investigated the potential use of electrospun DegraPol (degradable polyesterurethane) membranes as fibrous scaffolds for skeletal muscle tissue engineering. To evaluate their suitability for this specific application, scaffolds were characterised with reference to their morphological, degradative and mechanical properties. Subsequently, cell viability, adhesion and differentiation on coated (with collagen, fibronectin and Matrigel, a gelatinous protein mixture) and uncoated DegraPol electrospun membranes were investigated using murine and rat myoblast cell lines (C2C12 and L6 respectively) and primary human satellite cells. The electrospun DegraPol membranes showed satisfactory mechanical properties (linear elastic behaviour up to $10 \%$ deformation, $E$ modulus of the order of megapascals) and good cellular response in preliminary adhesion and differentiation experiments (cellular adherence and proliferation on differently coated electrospun membranes, accompanied with positive staining for myosin heavy chain).

Originally, in the field of liver tissue engineering, galactosylated nanofibre meshes were suggested as potential scaffolds by Chua et $a l^{21}$ In this study, highly porous nanofibre scaffolds of PCLEEP were grafted with poly(acrylic acid) and subsequently, covalently conjugated with galactose ligands. Hepatocytes, isolated from male Wister rats, cultured on galactosylated scaffolds, exhibited similar functional profile in terms of cell attachment, ammonia metabolism, albumin secretion and cytochrome P450 enzymatic activity as those on the functional two-dimensional substrate. Galactosylated PCLEEP nanofibre mesh demonstrated the unique properties of promoting hepatocyte aggregates within the mesh and around the fibres, forming an integrated spheroid nanofibre construct. Indeed, this construct would be advantageous in the design of bioartificial liver assisted devices.

Mechanical forces play a central role in the physiology of a wide variety of tissues. Several researchers ${ }^{10,142}$ have reported that cyclic mechanical stretch increases ECM production in cultured fibroblasts on flexible membranes. Additionally, when connective tissue cells are grown on deformable substrates and subject to an applied cyclic strain field, the cells align perpendicular to the greatest strain direction. Lee et al. ${ }^{80}$ studied the effect of fibre alignment in polyurethane nanofibres and direction of mechanical stimuli on the ECM generation of human ligament fibroblast (HLF). The results indicated that HLF cultured in aligned nanofibres had a similar morphology to ligament fibroblasts in vivo. The aligned structure led to increased ECM production, and the aligned HLFs were more sensitive to strain in the longitudinal direction. Consequently, aligned nanofibres can constitute a promising base material for tissue engineered ligament in that they are a biomimetic structure and provide the mechanical environment ligament fibroblasts encounter in vivo.

\section{Desired properties of electrospun nanofibres as scaffolds}

Tissue engineering is emerging as an alternative approach for the (re)generation of functional tissues damaged by disease or trauma, and in replacing failing or malfunctioning organs. Biomaterials play a significant role in these modern strategies of regenerative medicine and tissue engineering. They can be used to tailor the biophysical and biochemical milieus that direct cellular behaviour and function into the desired regeneration of tissues. Moreover, the scaffold should act as a template for the neovascularisation of the regenerated tissue and could actively participate in the regeneration process through the release of growth/differentiation factors. Various degradable biomaterials, either natural or synthetic, have been processed into scaffolds for tissue engineering. 1,6,44,45,99,106,107 Essentially, the success of tissue engineering methods is highly dependent on the properties of the scaffold. Basic scaffold design requirements include biodegradability, biocompatibility, high surface area/volume ratio (porosity and interconnectivity) and mechanical integrity. $1,55,63,119,141$ 
It is agreed $^{99,119}$ that a candidate scaffold should closely mimic the structural and functional properties of the materials found in the native ECM of the host tissue. Therefore, the ultimate goal of the scaffold is the production of an ideal structure that can replace the natural ECM until host cells can repopulate and resynthesize a new natural matrix. It is well known that most natural ECMs are composed of randomly oriented fibrils of nanometre scale diameters. The morphology and architecture of the electrospun structure aims at being similar to those of some natural ECMs. ${ }^{155,200}$ Biological performance is regulated by the biological signals from growth factors, extracellular matrix, and also by the surrounding cells. More sophisticated efforts to mimic this natural scaffold are being pursued by many groups that are exploring the development of biomaterial/biochemical composites incorporating biological agents such as growth factors and other key cell regulatory molecules. ${ }^{40,131}$ This objective has also been pursued using electrospun nanofibre meshes, although little attention has to date been given to the loading growth factors. ${ }^{20,143}$

The pores of a tissue engineering scaffold constitute the space in which the cells reside. It is generally agreed that a highly porous microstructure with interconnected pores and a large surface area is desirable to allow cell seeding and migration throughout the material. Furthermore, the scaffolds should exhibit adequate microporosity, to encourage capillary ingrowth. High porosity provides more opportunities for cell colonisation and makes the diffusion of gases, nutrients and metabolic waste between scaffold and environment more efficient. Given the importance of the pore structure of tissue engineering scaffolds, a variety of techniques have been proposed to obtain an appropriate substrate for cell culture. $8,22,23,30,44,46,47,56,63,76,105,114,120,127,128,153,154,156,168,176,184$

Many of these techniques employ organic solvents or high temperature, and the preservation of biocompatibility and the crystalline structure of the polymer are problematic. To overcome the above limitations, electrospun fibrous matrices can be used as alternative scaffolds in tissue engineering applications. When nanofibres are created in the electrostatic field, they are deposited randomly on the collector, layer by layer, and a wide variety of pore diameters (distances between fibres) are formed. ${ }^{60,68,74,100,193}$ However, the strongest limitations of nanofibrous structures are their inherent two-dimensional character and the difficulty in controlling pore size. In most tissue engineering applications, it is desirable to have scaffolds with a pore size that enables migration of the cells into the inner regions of the structure. The cells must remain viable, thus requiring an efficient exchange of nutrients and metabolites with the culture medium. The porosity of the electrospun meshes hinders the migration of cells, but is suitable for diffusion of nutrients and metabolites. Thus, new developments of the technology are needed to overcome the difficulty of cell migration when seeded at the mesh surface. Furthermore, the degree of porosity always influences other properties of the scaffolds such as mechanical stability, and its value should always be balanced with the mechanical needs of the particular tissue that is targeted.

The purpose of a scaffold is not only to provide a surface for cell residence but also to maintain mechanical stability at the host defect site. Mechanical stability is dependent primarily on the selection of the biomaterial, the architectural design of the scaffold and the cell-material interactions. ${ }^{1,63}$ A well designed tissue engineered scaffold has to meet, at least, two mechanical requirements to be effective. The scaffold must retain structural integrity and stability when a physician handles and implants it into the defect site of the host. After surgery, the structure at the implant site must provide sufficient biomechanical support during the process of tissue regeneration and structure degradation. Electrospun fibres have nanostructured surface morphologies with small pores that influence mechanical properties like tensile strength and modulus. ${ }^{49,74,137,201}$ Also, aligned nanofibre composites provide better mechanical properties than a randomly aligned nanofibre composite structure. ${ }^{70,147}$

It is also highly desirable to use processing methods that are efficient and that can be used to regulate the chemical, biological and material properties of the fabricated matrix. ${ }^{1,63}$ Methods such as solvent casting, ${ }^{120,153,154}$ fibre bonding, ${ }^{43,47,114,174}$ injection moulding, $22,23,46,156,168,176$ and rapid prototyping, ${ }^{30,56,76,128,184}$ among others, have been used for the fabrication of porous scaffolds. These scaffolds were proposed for tissue engineering of various tissues including bone, cartilage, tendon, blood vessel and heart valve. ${ }^{44,45,55,78,148}$ However, most of the scaffolds could only replace the lost tissue physically but not functionally. ${ }^{150}$ In electroprocessing, the shape of the scaffolding and orientation of fibres within an engineered matrix can be regulated by controlling the motion of target mandrel and source polymeric solution. Presumably, the incorporation of various degrees of cross-linking into this type of nonwoven matrix can be used to further tailor the material properties of the matrix to specific applications. As a processing strategy, electrospinning is rapid, efficient and inexpensive, and can be used to fabricate complex, reliable scaffolds. For example, blends $^{201}$ or laminates ${ }^{199}$ of different materials can be produced with this technique. Electrospinning can even be used to incorporate slight structural adjustments into an engineered material by regulating the orientation of nanofibres within the fabricated network. ${ }^{79,110,169,187,190}$

A significant advantage of the electrospinning process is the ability to fabricate non-woven, nanometre scale fibrous structures. ${ }^{134}$ The architecture of the scaffold is dynamically changed as the polymer fibres are hydrolyzed and degraded over time, which allows the colonising cells to build up their own ECM. ${ }^{90}$ Indeed, the main goal of tissue engineering is to develop a biocompatible scaffold material which is degradable over a controllable time scale into non-toxic products that may disappear together with new tissue formation, leaving natural tissue replacement. ${ }^{119}$ Thus, an electrospun structure composed of ultrafine nanofibres would be more susceptible to hydrolysis than thicker fibres when used to culture cells for tissue engineering applications, because of enhanced water contact due to the large surface area. ${ }^{89}$ However, the molecular weight decrease during in vitro degradation of electrospun PCL materials was much lower than those for solvent cast PCL films, which may be due to enhanced diffusion of oligomers out of the fibres (as a result of high surface/ volume ratio), which would reduce the effects of autocatalytic degradation. ${ }^{12}$ Bölgen and colleagues ${ }^{12}$ 


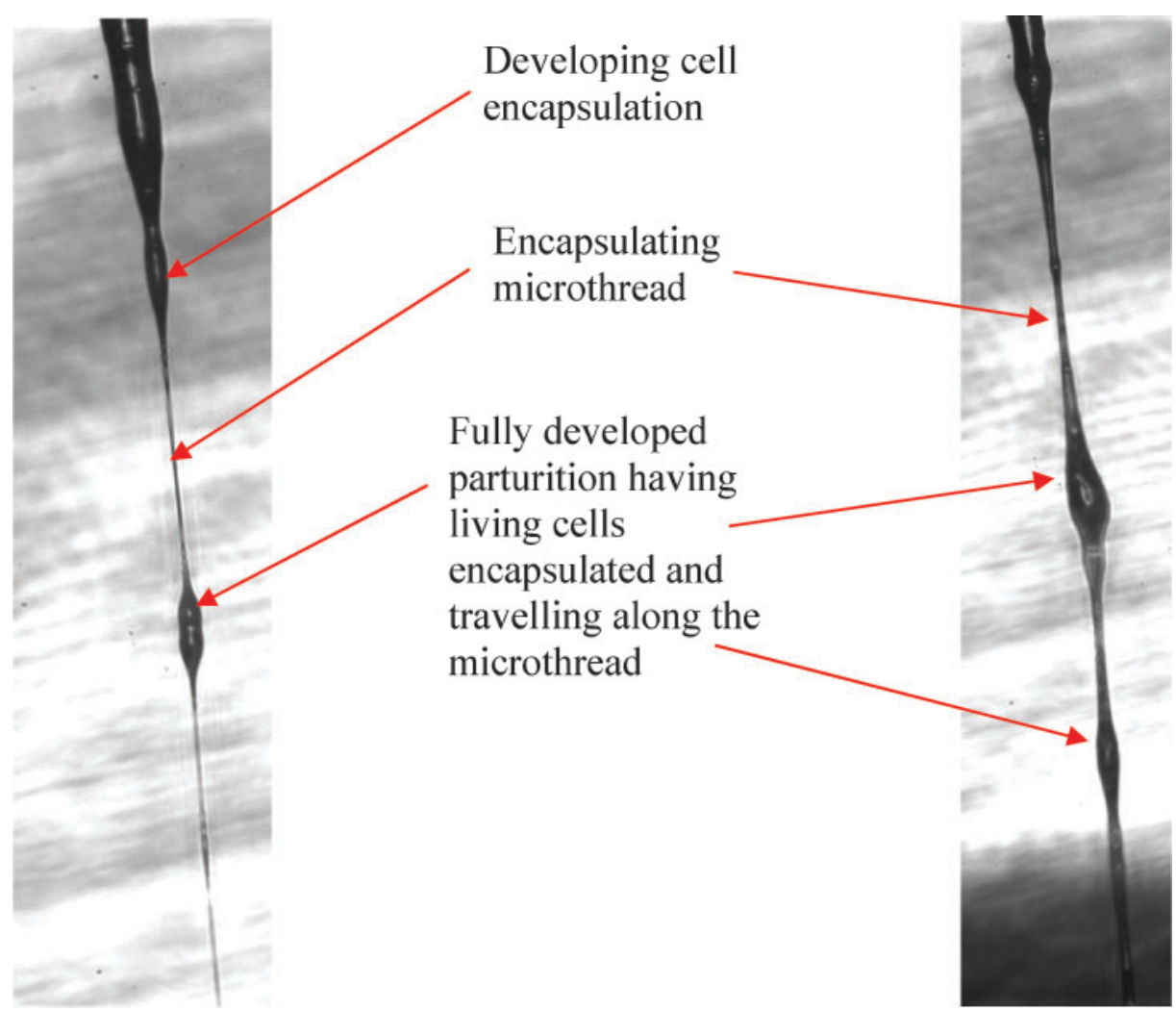

demonstrated a faster degradation rate in vivo than in vitro, attributed to the enzymatic degradation of PCL in addition to the hydrolytic degradation. Recently, Liang and collaborators ${ }^{95}$ established that the biodegradation rate, as well as the hydrophilicity of the electrospun scaffolds, could be finely turned with different material compositions (PLGA or PLA-b-PEG-b-PLA triblock copolymer and DNA). It was demonstrated that the electrospun scaffold containing those four compositions, which exhibited an ideal biodegradation profile, good hydrophilicity and stable mechanical properties in aqueous conditions, was suitable for biomedical applications including biodegradable scaffolds for tissue engineering and prevention of postoperative adhesions. ${ }^{72}$

\section{Future directions}

Electrospinning is a relatively old technology, ${ }^{37}$ which has appeared in the literature for more than 70 years. Despite the progress made in process modification and control, considerable challenges remain.

Improved process models are needed to achieve better understanding of the mechanisms and to explain observed phenomena such as pore formation in nanofibres during electrospinning ${ }^{13}$ and formation of hollow fibres. ${ }^{53,61,83,86,97}$ Another need is to model nanofibre deposition on substrates, both stationary and moving, to improve the nanofibre alignment when using newly developed processes, ${ }^{25,27,28,36,64,70,80,84,85,124,146,165,169-171,187,190}$ which may in itself lead to the development of novel techniques. Models for multiple jet electrospinning should also be improved, as well as the modelling of jet interactions. ${ }^{172}$ In summary, a fundamental experimental and theoretical analysis of the process is needed to develop flexible and reliable methods to fabricate nanofibres and their assemblies and composites. ${ }^{32}$

To date, most of the electrospun fibres obtained have been synthetic. More attention should be given to natural biopolymers, with the aim of achieving fibres with better biocompatibility and performance. The present authors believe that the successful conversion of natural biopolymers into ultrafine and nanofibrous structures will provide new opportunities and enhance the possibilities of their use in bioengineering and other demanding applications.

Core/sheath or hollow nanofibres are a more recent revolutionary product of electrospinning. Application of those structures in tissue engineering and regenerative medicine will, it is hoped, allow drugs, growth factors, enzymes, peptides or even DNA to be embedded into the core of biodegradable polymer nanofibres, and released as requried. ${ }^{102}$ In addition, using a synthetic polymer as the core material and natural polymer as the shell material, nanofibres with strong mechanical strength and good biocompatibility should be obtained. ${ }^{199}$

Recently, ${ }^{57,173}$ the possibility of producing encapsulated cells in microfibres (termed microthreads by the authors) and meshes by electrospinning technology has been explored (Fig. 10). In this approach, immortalised (human brain astrocytoma cell line) and primary cells (porcine vascular and rabbit aorta smooth muscle cells) were loaded into poly(dimethylsiloxane) nanofibres, using a coaxial needle configuration. It was demonstrated that electrospun cells remain viable over long culture periods, showing no evidence of cellular damage. Work pioneering the incorporation of living cells into electrospun nanofibres was carried out by Lee et al. ${ }^{81}$ and Salalha et al., ${ }^{140}$ demonstrating efficient encapsulation of viruses (M13) and bacteria (Escherichia coli and 


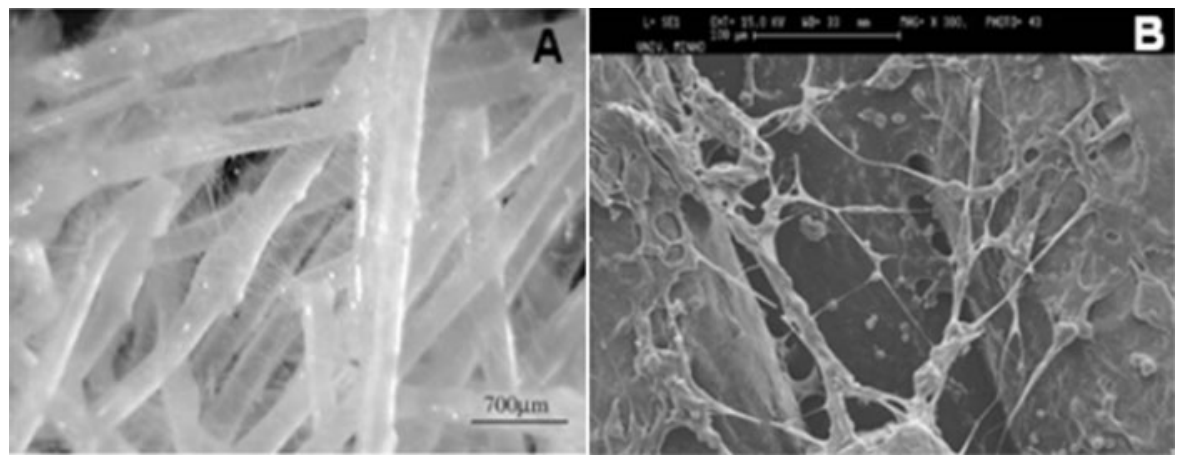

11 A optical micrograph of micro-/nanofibre combined scaffolds and B SEM image of human osteoblast like cells (Saos2) seeded on nano- and microfibre combined scaffolds after 14 days of culture (adapted from Ref. 174: $\odot 2005$ Springer)

Staphylococcus albus). Another approach ${ }^{157,158}$ used rat aorta vascular SMCs electrosprayed simultaneously with elecrospun poly(ester urethane) urea to produce a hybrid tissue engineered construct. This approach, denominated by 'cellular microintegration', was proposed in the context of blood vessel replacement, aiming to seed the cells during fabrication of nanofibrous tubular scaffolds. Indeed, these biomicrofabrication methods allow the production of biohybrid scaffolds with promising applications in regenerative medicine, an approach that will surely be further explored in future.

Biomaterial scaffolds are designed to support cell and tissue growth, aiming on a macroscopic level to match the properties of the organs to be replaced, without being able to recreate the complexity and nanoscale detail observed in real organs at the level of the matrix interaction. ${ }^{160}$ The ability to engineer materials to a similar level of complexity may become a reality, through the fabrication of novel biodegradable polymeric matrices by combining electrospinning methodologies with well established techniques for materials processing (e.g. injection moulding, solvent casting, three-dimensional plotting). For example, a threedimensional micro-/nanostructure comprising electrospun nanofibres deposited on a wet spun microfibre scaffold has recently been developed ${ }^{174}$ (Fig. 11). Its biological functionality was demonstrated by the culturing of human osteoblast like cells, bone marrow stromal cells and endothelial cells (HUVECs and microvascular endothelial cells). ${ }^{144,145,174}$ This hierarchical structure was developed to mimic the highly organised fibrous structures of bone tissue, not forgetting the vascular system. Combining nanostructured scaffold structures with the incorporation of biological signals into the scaffold fabric is also likely to prove a most rewarding approach. $^{99}$

\section{Acknowledgements}

Figures 2, 9 and 11 have been adapted and reproduced with the authors' consent. Figures 4 and 10 are reproduced with permission from ACS Publishing, Figs. 5 and 6 with permission from Wiley-VCH Verlag $\mathrm{GmbH} \& \mathrm{Co}$. KGaA and Fig. 8 with permission from Elsevier.

\section{References}

1. C. M. Agrawal and R. B. Ray: J. Biomed. Mater. Res., 2001, 55, $141-150$.
2. B. Alberts, A. Johnson, J. Lewis, M. Raff, K. Roberts and P. Walter: in 'Molecular biology of the cell' (ed. B. Alberts et al.); 2002, London, Garland Science.

3. M. Alves da Silva, A. Crawford, J. Mundy, A. Martins, J. V. Araujo, P. V. Hatton, R. L. Reis and N. M. Neves: Tissue Eng., 2008, 14, In press.

4. J. V. Araujo, A. Martins, I. B. Leonor, E. D. Pinho, R. L. Reis and N. M. Neves: J. Biomed. Mater. Res. Polym. Ed., 2008, 19, 1239-1256.

5. N. Ashammakhi, A. Ndreu, A. M. Piras, L. Nikkola, T. Sindelar, H. Ylikauppila, A. Harlin, M. E. Gomes, N. M. Neves, E. Chiellini, F. Chiellini, V. Hasirci, H. Redl and R. L. Reis: J. Nanosci. Nanotechnol., 2007, 7, 862-882.

6. H. S. Azevedo, M. E. Gomes, P. B. Malafaya, A. P. Marques, A. J. Salgado and R. L. Reis: in 'Handbook of biodegradable polymeric materials and their applications' (ed. S. Mallapragada and B. Narasimhan), 13-31; 2006, Stevenson Ranch, CA, American Scientific Publishers.

7. B. M. Baker and R. L. Mauck: Biomaterials, 2007, 28, 1967-1977.

8. E. T. Baran, K. Tuzlakoglu, A. J. Salgado and R. L. Reis: J. Mater. Sci., Mater. Med., 2004, 15, 161-165.

9. C. P. Barnes, S. A. Sell, E. D. Boland, D. G. Simpson and G. L. Bowlin: Adv. Drug Deliv. Rev., 2007, 59, 1413-1433.

10. C. C. Berry, C. Cacou, D. A. Lee, D. L. Bader and J. C. Shelton: Biorheology, 2002, 40, 337-345.

11. N. Bhattarai, D. Edmondson, O. Veiseh, F. A. Matsen and M. Q. Zhang: Biomaterials, 2005, 26, 6176-6184.

12. N. Bölgen, Y. Z. Menceloglu, K. Acatay, I. Vargel and E. Pişkin: J. Biomater. Sci. Polym. Ed., 2005, 16, 1537-1555.

13. M. Bognitzki, W. Czado, T. Frese, A. Schaper, M. Hellwig, M. Steinhart, A. Greiner and J. H. Wendorff: Adv. Mater., 2001, 13, $70-72$.

14. M. Bognitzki, T. Frese, M. Steinhart, A. Greiner, J. H. Wendorff, A. Schaper and M. Hellwig: Polym. Eng. Sci., 2001, 41, 982-989.

15. E. D. Boland, T. A. Telemeco, D. G. Simpson, G. E. Wnek and G. L. Bowlin: J. Biomed. Mater. Res. B, Appl. Biomater., 2004, 71B, 144-152.

16. E. D. Boland, G. E. Wnek, D. G. Simpson, K. J. Pawlowski and G. L. Bowlin: J. Macromol. Sci., Pure Appl. Chem., 2001, 38, 1231-1243.

17. U. Boudriot, B. Goetz, R. Dersch, A. Greiner and J. H. Wendorff: Macromol. Symp., 2005, 225, 9-16.

18. D. Briggs: 'Surface analysis of polymers by XPS and static SIMS', 14 46; 1998, Cambridge, Cambridge University Press.

19. C. J. Buchko, K. M. Kozloff, A. Sioshansi, K. S. O'Shea and D. C. Martin: Proc. Materials Research Society Symposium, Boston, MA, USA, Materials Research Society, 1996, 23-28.

20. S. Y. Chew, J. Wen, E. K. F. Yim and K. W. Leong: Biomacromolecules, 2005, 6, 2017-2024.

21. K. N. Chua, W. S. Lim, P. C. Zhang, H. F. Lu, J. Wen, S. Ramakrishna, K. W. Leong and H. Q. Mao: Biomaterials, 2005, 26, 2537-2547.

22. V. M. Correlo, L. F. Boesel, M. Bhattacharya, J. F. Mano, N. M. Neves and R. L. Reis: Mater. Sci. Eng. A, 2005, A403, 57-68.

23. V. M. Correlo, E. D. Pinho, I. Pashkuleva, M. Bhattacharya, N. M. Neves and R. L. Reis: Macromol. Biosci., 2007, 7, 354-363.

24. D. A. Czaplewski, S. S. Verbridge, J. Kameoka and H. G. Craighead: Nano Lett., 2004, 4, 437-439.

25. P. D. Dalton, D. Klee and M. Moller: Polymer, 2005, 46, 611-614. 
26. J. M. Deitzel, J. Kleinmeyer, D. Harris and N. C. Beck Tan: Polymer, 2001, 42, 261-272.

27. J. M. Deitzel, J. D. Kleinmeyer, J. K. Hirvonen and N. C. Beck Tan: Polymer, 2001, 42, 8163-8170.

28. R. Dersch, T. Q. Liu, A. K. Schaper, A. Greiner and J. H. Wendorff: J. Polym. Sci. A, Polym. Chem., 2003, 41A, 545-553.

29. R. Dersch, M. Steinhart, U. Boudriot, A. Greiner and J. H Wendorff: Polym. Adv. Technol., 2005, 16, 276-282.

30. B. Dhariwala, E. Hunt and T. Boland: Tissue Eng., 2004, 10, 1316-1322.

31. J. Doshi and D. H. Reneker: J. Electrostat., 1995, 35, 151-160.

32. Y. Dzenis: Science, 2004, 304, 1917-1919.

33. D. Fang, B. S. Hsiao and B. Chu: Proc. 14th Annual Int. TANDEC Nonwovens Conf., Knoxville, TN, USA, November 2004, University of Tennessee, 1-11.

34. X. Fang and D. H. Reneker: J. Macromol. Sci. Phys., 1997, 36, 169-173.

35. R. G. Flemming, C. J. Murphy, G. A. Abrams, S. L. Goodman and P. F. Nealey: Biomaterials, 1999, 20, 573-588.

36. H. Fong, W. Liu, C. S. Wang and R. A. Vaia: Polymer, 2002, 43, 775-780.

37. A. Formhals: US Patent 1975504, 1934

38. A. Frenot and I. S. Chronakis: Curr. Opin. Colloid Interf. Sci., $2003,8,64-67$.

39. K. Fujihara, M. Kotaki and S. Ramakrishna: Biomaterials, 2005 , 26, 4139-4147.

40. A. Gallardo, G. A. Abraham, C. Elvira, B. Vázquez and J. San Román: in 'Polymer based systems on tissue engineering, replacement and regeneration' (ed. R. L. Reis and D. Cohn), 37-52; 2002, Dordrecht, Kluwer Academic Publishers.

41. A. M. Gañán-Calvo, J. Dávila and A. Barrero: J. Aerosol Sci. 1997, 28, 249-275.

42. X. Y. Geng, O. H. Kwon and J. H. Jang: Biomaterials, 2005, 26, 5427-5432.

43. M. E. Gomes, J. S. Godinho, D. Tchalamov, A. M. Cunha and R. L. Reis: Mater. Sci. Eng. C, 2002, C20, 19-26.

44. M. E. Gomes and R. L. Reis: Int. Mater. Rev., 2004, 49, 261-273.

45. M. E. Gomes and R. L. Reis: Macromol. Biosci., 2004, 4, 737-742.

46. M. E. Gomes, A. S. Ribeiro, P. B. Malafaya, R. L. Reis and A. M. Cunha: Biomaterials, 2001, 22, 883-889.

47. M. E. Gomes, V. I. Sikavitsas, E. Behravesh, R. L. Reis and A. G Mikos: J. Biomed. Mater. Res. A, 2003, 67A, 87-95.

48. A. Greiner, J. H. Wendorff, A. L. Yarin and E. Zussman: Appl. Microbiol. Biot., 2006, 71, 387-393.

49. W. He, Z. W. Ma, T. Yong, W. E. Teo and S. Ramakrishna: Biomaterials, 2005, 26, 7606-7615.

50. T. V. How: US Patent 4552707, 1985.

51. C. M. Hsu and S. Shivkumar: J. Mater. Sci., 2004, 39, 3003-3013.

52. L. Huang, K. Nagapudi, R. P. Apkarian and E. L. Chaikof: J. Biomater. Sci. Polym. Ed., 2001, 12, 979-993.

53. Z. M. Huang, Y. Zhang and S. Ramakrishna: J. Polym. Sci. B, Polym. Phys., 2005, 43B, 2852-2861.

54. Z. M. Huang, Y. Z. Zhang, M. Kotaki and S. Ramakrishna: Compos. Sci. Technol., 2003, 63, 2223-2253.

55. D. W. Hutmacher: Biomaterials, 2000, 21, 2529-2543.

56. D. W. Hutmacher, T. Schantz, I. Zein, N. Kee Woei, T. Swee Hin and T. Kim Cheng: J. Biomed. Mater. Res., 2001, 55, 203-216.

57. S. N. Jayasinghe, S. Irvine and J. R. McEwan: Nanomedicine, 2007, 2, 555-567.

58. S. I. Jeong, S. Y. Kim, S. K. Cho, M. S. Chong, K. S. Kim, H Kim, S. B. Lee and Y. M. Lee: Biomaterials, 2007, 28, 1115-1122.

59. H. Jiang, D. Fang, B. S. Hsiao, B. Chu and W. Chen: Biomacromolecules, 2004, 5, 326-333.

60. H. L. Jiang, D. F. Fang, B. J. Hsiao, B. J. Chu and W. L. Chen: J. Biomater. Sci. Polym. Ed., 2004, 15, 279-296.

61. H. L. Jiang, Y. Q. Hu, P. C. Zhao, Y. Li and K. J. Zhu: J. Biomed. Mater. Res. B, Appl. Biomater., 2006, 79B, 50-57.

62. H. J. Jin, J. S. Chen, V. Karageorgiou, G. H. Altman and D. L. Kaplan: Biomaterials, 2004, 25, 1039-1047.

63. T. S. Karande, J. L. Ong and C. M. Agrawal: Ann. Biomed. Eng., 2004, 32, 1728-1743.

64. P. Katta, M. Alessandro, R. D. Ramsier and G. G. Chase: Nano Lett., 2004, 4, 2215-2218.

65. D. S. Katti, K. W. Robinson, F. K. Ko and C. T. Laurencin: J. Biomed. Mater. Res. B, Appl. Biomater., 2004, 70B, 286-296.

66. E. R. Kenawy, G. L. Bowlin, K. Mansfield, J. Layman, D. G Simpson, E. H. Sanders and G. E. Wnek: J. Control. Release, 2002, 81, 57-64
67. E. R. Kenawy, J. M. Layman, J. R. Watkins, G. L. Bowlin, J. A. Matthews, D. G. Simpson and G. E. Wnek: Biomaterials, 2003, 24, 907-913.

68. M. S. Khil, S. R. Bhattarai, H. Y. Kim, S. Z. Kim and K. H. Lee: J. Biomed. Mater. Res. B, Appl. Biomater., 2005, 72B, 117-124.

69. M. S. Khil, D. I. Cha, H. Y. Kim, I. S. Kim and N. Bhattarai: J. Biomed. Mater. Res. B, Appl. Biomater., 2003, 67B, 675-679.

70. J. S. Kim and D. H. Reneker: Polym. Eng. Sci., 1999, 39, 849-854.

71. K. Kim, Y. K. Luu, C. Chang, D. F. Fang, B. S. Hsiao, B. Chu and M. Hadjiargyrou: J. Control. Release, 2004, 98, 47-56.

72. K. Kim, M. Yu, X. Zong, J. Chiu, D. Fang, Y. S. Seo, B. S. Hsiao, B. Chu and M. Hadjiargyrou: Biomaterials, 2003, 24, 4977-4985.

73. S. Koombhongse, W. Liu and D. H. Reneker: J. Polym. Sci. B, Polym. Phys., 2001, 39B, 2598-2606.

74. I. K. Kwon, S. Kidoaki and T. Matsuda: Biomaterials, 2005, 26, 3929-3939.

75. S. Kidoaki, I. K. Kwon and T. Matsuda: Biomaterials, 2005, 26, 37-46.

76. R. Landers, A. Pfister, U. Hübner, H. John, R. Schmelzeisen and R. Mülhaupt: J. Mater. Sci., 2002, 37, 3107-3116.

77. R. Langer and J. P. Vacanti: Science, 1993, 260, 920-926.

78. C. T. Laurencin, A. M. A. Ambrosio, M. D. Borden and J. A. Cooper, Jr: Annu. Rev. Biomed. Eng., 1999, 1, 19-46.

79. J. M. Layman, E.-R. Kenawy, J. R. Watkins, M. E. Carrjr, G. L. Bowlin and G. E. Wnek: Polym. Prepr., 2003, 44, 94-95.

80. C. H. Lee, H. J. Shin, I. H. Cho, Y. M. Kang, I. A. Kim, K. D. Park and J. W. Shin: Biomaterials, 2005, 26, 1261-1270.

81. S.-W. Lee and A. M. Belcher: Nano Lett., 2004, 4, 387-390.

82. C. M. Li, C. Vepari, H. J. Jin, H. J. Kim and D. L. Kaplan: Biomaterials, 2006, 27, 3115-3124.

83. D. Li, A. Babel, S. A. Jenekhe and Y. N. Xia: Adv. Mater., 2004, 16, 2062-2066.

84. D. Li, Y. L. Wang and Y. N. Xia: Nano Lett., 2003, 3, 1167-1171.

85. D. Li, Y. L. Wang and Y. N. Xia: Adv. Mater., 2004, 16, 361-366.

86. D. Li and Y. N. Xia: Nano Lett., 2004, 4, 933-938.

87. D. Li and Y. N. Xia: Adv. Mater., 2004, 16, 1151-1170.

88. M. Y. Li, M. J. Mondrinos, M. R. Gandhi, F. K. Ko, A. S. Weiss and P. I. Lelkes: Biomaterials, 2005, 26, 5999-6008.

89. W. J. Li, K. G. Danielson, P. G. Alexander and R. S. Tuan: J. Biomed. Mater. Res. A, 2003, 67A, 1105-1114.

90. W. J. Li, C. T. Laurencin, E. J. Caterson, R. S. Tuan and F. K. Ko: J. Biomed. Mater. Res., 2002, 60, 613-621.

91. W. J. Li, R. L. Mauck, J. A. Cooper, X. Yuan and R. S. Tuan: J. Biomech., 2007, 40, 1686-1693.

92. W. J. Li, R. L. Mauck and R. S. Tuan: J. Biomed. Nanotechnol., 2005, 1, 259-275.

93. W. J. Li, R. Tuli, X. X. Huang, P. Laquerriere and R. S. Tuan: Biomaterials, 2005, 26, 5158-5166.

94. W. J. Li, R. Tuli, C. Okafor, A. Derfoul, K. G. Danielson, D. J. Hall and R. S. Tuan: Biomaterials, 2005, 26, 599-609.

95. D. H. Liang, Y. K. Luu, K. S. Kim, B. S. Hsiao, M. Hadjiargyrou and B. Chu: Nucleic Acids Res., 2005, 33, 1-8.

96. H. Liu, J. Kameoka, D. A. Czaplewski and H. G. Craighead: Nano Lett., 2004, 4, 671-675.

97. I. G. Loscertales, A. Barrero, M. Marquez, R. Spretz, R. VelardeOrtiz and G. Larsen: J. Am. Chem. Soc., 2004, 126, 5376-5377.

98. E. Luong-Van, L. Grondahl, K. N. Chua, K. W. Leong, V. Nurcombe and S. M. Cool: Biomaterials, 2006, 27, 2042-2050.

99. M. P. Lutolf and J. A. Hubbell: Nature Biotechno., 2005, 23, 4755.

100. Y. K. Luu, K. Kim, B. S. Hsiao, B. Chu and M. Hadjiargyrou: J. Control. Release, 2003, 89, 341-353.

101. J. Lyons, C. Li and F. Ko: Polymer, 2004, 45, 7597-7603.

102. Z. W. Ma, M. Kotaki, R. Inai and S. Ramakrishna: Tissue Eng., 2005, 11, 101-109.

103. Z. W. Ma, M. Kotaki, T. Yong, W. He and S. Ramakrishna: Biomaterials, 2005, 26, 2527-2536.

104. A. G. MacDiarmid, W. E. Jones, Jr, I. D. Norris, J. Gao, A. T. Johnson. Jr, N. J. Pinto, J. Hone, B. Han, F. K. Ko, H. Okuzaki and M. Llaguno: Synth. Met., 2001, 119, 27-30.

105. P. B. Malafaya, C. Elvira, A. Gallardo, J. San Román and R. L. Reis: J. Biomater. Sci. Polym. Ed., 2001, 12, 1227-1241.

106. P. B. Malafaya, M. E. Gomes, A. J. Salgado and R. L. Reis: $A d v$. Exp. Med. Biol., 2003, 534, 201-233.

107. J. F. Mano, G. A. Silva, H. S. Azevedo, P. B. Malafaya, R. A. Sousa, S. S. Silva, L. F. Boesel, J. M. Oliveira, T. C. Santos, A. P. Marques, N. M. Neves and R. L. Reis: J. R. Soc. Interf., 2007, 4, 999-1030. 
108. A. Martins, J. V. Araujo, R. L. Reis and N. M. Neves: Nanomedicine, 2007, 2, 929-942.

109. J. A. Matthews, E. D. Boland, G. E. Wnek, D. G. Simpson and G. L. Bowlin: J. Bioact. Compat. Polym., 2003, 18, 125-134.

110. J. A. Matthews, G. E. Wnek, D. G. Simpson and G. L. Bowlin: Biomacromolecules, 2002, 3, 232-238.

111. M. C. McManus, E. D. Boland, D. G. Simpson, C. P. Barnes and G. L. Bowlin: J. Biomed. Mater. Res. A, 2007, 81A, 299-309.

112. C. Meechaisue, P. Wutticharoenmongkol, R. Waraput, T. Huangjing, N. Ketbumrung, P. Pavasant and P. Supaphol: Biomed. Mater., 2007, 2, 181-188.

113. S. Megelski, J. S. Stephens, D. Bruce Chase and J. F. Rabolt: Macromolecules, 2002, 35, 8456-8466.

114. A. G. Mikos, Y. Bao, L. G. Cima, D. E. Ingber, J. P. Vacanti and R. Langer: J. Biomed. Mater. Res., 1992, 27, 183-189.

115. B. M. Min, L. Jeong, Y. S. Nam, J. M. Kim, J. Y. Kim and W. H Park: Int. J. Biol. Macromol., 2004, 34, 281-288.

116. B. M. Min, G. Lee, S. H. Kim, Y. S. Nam, T. S. Lee and W. H Park: Biomaterials, 2004, 25, 1289-1297.

117. B. M. Min, Y. You, J. M. Kim, S. J. Lee and W. H. Park Carbohyd. Polym., 2004, 57, 285-292.

118. X. M. Mo, C. Y. Xu, M. Kotaki and S. Ramakrishna: Biomaterials, 2004, 25, 1883-1890.

119. D. J. Mooney and A. G. Mikos: Sci. Am., 1999, 280, 60-65.

120. W. L. Murphy, R. G. Dennis, J. L. Kileny and D. J. Mooney: Tissue Eng., 2002, 8, 43-52.

121. R. Murugan and S. Ramakrishna: Tissue Eng., 2007, 13, 18451866.

122. L. S. Nair, S. Bhattacharyya, J. D. Bender, Y. E. Greish, P. W Brown, H. R. Allcock and C. T. Laurencin: Biomacromolecules, 2004, 5, 2212-2220.

123. A. Ndreu, L. Nikkola, H. Ylikauppila, N. Ashammakhi and V. Hasirci: Nanomedicine, 2008, 3, 45-60.

124. N. L. Nerurkar, D. M. Elliott and R. L. Mauck: J. Orthop. Res., 2007, 25, 1018-1028.

125. N. M. Neves, R. Campos, A. Pedro, J. Cunha, F. Macedo and R. L. Reis: Int. J. Nanomed., 2007, 2, 1-16.

126. K. Ohkawa, D. I. Cha, H. Kim, A. Nishida and H. Yamamoto: Macromol. Rapid Commun., 2004, 25, 1600-1605.

127. A. L. Oliveira, P. B. Malafaya and R. L. Reis: Biomaterials, 2003, 24, 2575-2584.

128. A. Pfister, R. Landers, A. Laib, U. Hübner, R. Schmelzeisen and R. Mülhaupt: J. Polym. Sci. A, Polym. Chem., 2004, 42A, 624 638.

129. Q. P. Pham, U. Sharma and A. G. Mikos: Tissue Eng., 2006, 12, 1197-1211.

130. Q. P. Pham, U. Sharma and A. G. Mikos: Biomacromolecules, 2006, 7, 2796-2805.

131. O. Pillai and R. Panchagnula: Curr. Opin. Chem. Biol., 2001, 5, $447-451$.

132. L. Pinchuk, J. B. Martin, Jr and A. A. Maurin: US Patent 5376117, 1994.

133. H. M. Powell, D. M. Supp and S. T. Boyce: Biomaterials, 2008, 29, 834-843.

134. D. H. Reneker and I. Chun: Nanotechnology, 1996, 7, 216-223.

135. K. S. Rho, L. Jeong, G. Lee, B. M. Seo, Y. J. Park, S. D. Hong, S Roh, J. J. Cho, W. H. Park and B. M. Min: Biomaterials, 2006, 27, 1452-1461.

136. S. A. Riboldi, N. Sadr, L. Pigini, P. Neuenschwander, M Simonet, P. Mognol, M. Sampaolesi, G. Cossu and S. Mantero: J. Biomed. Mater. Res. A, 2008, 84A, 1094-1101.

137. S. A. Riboldi, M. Sampaolesi, P. Neuenschwander, G. Cossu and S. Mantero: Biomaterials, 2005, 26, 4606-4615.

138. G. C. Rutledge and S. V. Fridrikh: Adv. Drug Deliv. Rev., 2007, 59, 1384-1391.

139. S. Sahoo, H. Ouyang, J. C. H. Goh, T. E. Tay and S. L. Toh: Tissue Eng., 2006, 12, 91-99.

140. W. Salalha, J. Kuhn, Y. Dror and E. Zussman: Nanotechnology, 2006, 17, 4675-4681.

141. A. J. Salgado, O. P. Coutinho and R. L. Reis: Macromol. Biosci., 2004, 4, 743-765.

142. V. V. Sambajon, J. E. Cillo, Jr, R. J. Gassner and M. J. Buckley: J. Oral Maxil. Surg., 2003, 61, 707-712.

143. E. H. Sanders, R. Kloefkorn, G. L. Bowlin, D. G. Simpson and G. E. Wnek: Macromolecules, 2003, 36, 3803-3805.

144. M. I. Santos, S. Fuchs, M. E. Gomes, R. E. Unger, R. L. Reis and C. J. Kirkpatrick: Biomaterials, 2007, 28, 240-248.

145. M. I. Santos, K. Tuzlakoglu, M. E. Gomes, S. Fuchs, R. E Unger, E. Piskin, R. L. Reis and C. J. Kirkpatrick: Tissue Eng., 2006, 12, 986-987.
146. E. Schnell, K. Klinkhammer, S. Balzer, G. Brook, D. Klee, P. Dalton and J. Mey: Biomaterials, 2007, 28, 3012-3025.

147. H. Schreuder-Gibson, P. Gibson, K. Senecal, M. Sennett, J. Walker, W. Yeomans, D. Ziegler and P. P. Tsai: J. Adv. Mater., 2002, 34, 44-55.

148. B. L. Seal, T. C. Otero and A. Panitch: Mater. Sci. Eng. Rep., 2001, 34, 147-230.

149. L. S. Sefcik, R. A. Neal, S. N. Kaszuba, A. M. Parker, A. J. Katz, R. C. Ogle and E. A. Botchwey: J. Tissue Eng. Reg. Med., 2008, 2, 210-220.

150. H. Shin, S. Jo and A. G. Mikos: Biomaterials, 2003, 24, 43534364 .

151. M. Shin, O. Ishii, T. Sueda and J. P. Vacanti: Biomaterials, 2004, 25, 3717-3723.

152. M. Shin, H. Yoshimoto and J. P. Vacanti: Tissue Eng., 2004, 10, 33-41.

153. R. M. Silva, C. Elvira, J. F. Mano, J. San Román and R. L. Reis: J. Mater. Sci., Mater. Med., 2004, 15, 523-528.

154. R. M. Silva, G. A. Silva, O. P. Coutinho, J. F. Mano and R. L. Reis: J. Mater. Sci., Mater. Med., 2004, 15, 1105-1112.

155. L. A. Smith and P. X. Ma: Colloid Surf. B, 2004, 39B, 125-131.

156. R. A. Sousa, G. Kalay, R. L. Reis, A. M. Cunha and M. J. Bevis: J. Appl. Polym. Sci., 2000, 77, 1303-1315.

157. J. J. Stankus, J. Guan, K. Fujimoto and W. R. Wagner: Biomaterials, 2006, 27, 735-744.

158. J. J. Stankus, L. Soletti, K. Fujimoto, Y. Hong, D. A. Vorp and W. R. Wagner: Biomaterials, 2007, 28, 2738-2746.

159. M. D. Stenoien, W. J. Drasler, R. J. Scott and M. L. Jenson: US Patent 5866217, 1999.

160. M. M. Stevens and J. H. George: Science, 2005, 310, 1135-1138.

161. J. Stitzel, L. Liu, S. J. Lee, M. Komura, J. Berry, S. Soker, G. Lim, M. van Dyke, R. Czerw, J. J. Yoo and A. Atala: Biomaterials, 2006, 27, 1088-1094.

162. J. D. Stitzel, K. J. Pawlowski, G. E. Wnek, D. G. Simpson and G. L. Bowlin: J. Biomater. Appl., 2001, 16, 22-33.

163. T. Subbiah, G. S. Bhat, R. W. Tock, S. Pararneswaran and S. S. Ramkumar: J. Appl. Polym. Sci., 2005, 96, 557-569.

164. A. Subramanian, D. Vu, G. F. Larsen and H. Y. Lin: J. Biomater. Sci. Polym. Ed., 2005, 16, 861-873.

165. B. Sundaray, V. Subramanian, T. S. Natarajan, R. Z. Xiang, C. C. Chang and W. S. Fann: Appl. Phys. Lett., 2004, 84, 1222-1224.

166. S. H. Tan, R. Inai, M. Kotaki and S. Ramakrishna: Polymer, $2005,46,6128-6134$

167. G. Taylor: Proc. R. Soc., 1964, 280, 383-397.

168. J. S. Temenoff and A. G. Mikos: Biomaterials, 2000, 21, 2405 2412 .

169. W. E. Teo, M. Kotaki, X. M. Mo and S. Ramakrishna: Nanotechnology, 2005, 16, 918-924.

170. W. E. Teo and S. Ramakrishna: Nanotechnology, 2005, 16, 1878 1884.

171. A. Theron, E. Zussman and A. L. Yarin: Nanotechnology, 2001, 12, 384-390.

172. S. A. Theron, A. L. Yarin, E. Zussman and E. Kroll: Polymer, 2005, 46, 2889-2899.

173. A. Townsend-Nicholson and S. N. Jayasinghe: Biomacromolecules, 2006, 7, 3364-3369.

174. K. Tuzlakoglu, N. Bolgen, A. J. Salgado, M. E. Gomes, E. Piskin and R. L. Reis: J. Mater. Sci., Mater. Med., 2005, 16, 1099-1104.

175. L. Van Vaeck, A. Adriaens and R. Gijbels: Mass Spectrom. Rev., 1999, 18, 1-47.

176. C. M. Vaz, P. F. N. M. van Doeveren, R. L. Reis and A. M. Cunha: Biomacromolecules, 2003, 4, 1520-1529.

177. J. Venugopal, Y. Z. Zhang and S. Ramakrishna: Nanotechnology, 2005, 16, 2138-2142.

178. G. Verreck, I. Chun, J. Peeters, J. Rosenblatt and M. E. Brewster: Pharm. Res., 2003, 20, 810-817.

179. G. Verreck, I. Chun, J. Rosenblatt, J. Peeters, A. van Dijck, J. Mensch, M. Noppe and M. E. Brewster: J. Control. Release, 2003, 92, 349-360.

180. E. Vinard, G. Lesèche, B. Andreassian and D. Costagliola: Ann. Vasc. Surg., 1999, 13, 141-150.

181. S. Wang, W. Cui and J. Bei: Anal. Bionanal. Chem., 2005, 381, $547-556$.

182. S. K. Williams and B. E. Jarrell: Nature Med., 1996, 2, 32-34.

183. G. E. Wnek, M. E. Carr, D. G. Simpson and G. L. Bowlin: Nano Lett., 2003, 3, 213-216.

184. T. B. F. Woodfield, J. Malda, J. de Wijn, F. Peters, J. Riesle and C. A. van Blitterswijk: Biomaterials, 2004, 25, 4149-4161.

185. P. Wutticharoenmongkol, N. Sanchavanakit, P. Pavasant and P. Supaphol: Macromol. Biosci., 2006, 6, 70-77. 
186. X. J. Xin, M. Hussain and J. J. Mao: Biomaterials, 2007, 28, 316 325

187. C. Y. Xu, R. Inai, M. Kotaki and S. Ramakrishna: Biomaterials, 2004, 25, 877-886

188. C. Y. Xu, R. Inai, M. Kotaki and S. Ramakrishna: Tissue Eng., 2004, 10, 1160-1168.

189. C. Y. Xu, F. Yang, S. Wang and S. Ramakrishna: J. Biomed. Mater. Res. A, 2004, 71A, 154-161.

190. F. Yang, R. Murugan, S. Wang, and S. Ramakrishna: Biomaterials, 2005, 26, 2603-2610.

191. F. Yang, C. Y. Xu, M. Kotaki, S. Wang, and S. Ramakrishna: J. Biomater. Sci. Polym. Ed., 2004, 15, 1483-1497.

192. A. L. Yarin, S. Koombhongse and D. H. Reneker: J. Appl. Phys., 2001, 89, 3018-3026.

193. H. Yoshimoto, Y. M. Shin, H. Terai and J. P. Vacanti: Biomaterials, 2003, 24, 2077-2082.

194. J. H. Yu, S. V. Fridrikh and G. C. Rutledge: Adv. Mater., 2004, 16, 1562-1566.

195. N. Zagris: Micron, 2001, 32, 427-438.

196. J. Zeng, A. Aigner, F. Czubayko, T. Kissel, J. H. Wendorff and A. Greiner: Biomacromolecules, 2005, 6, 1484-1488.
197. J. Zeng, X. Chen, X. Xu, Q. Liang, X. Bian, L. Yang and X. Jing: J. Appl. Polym. Sci., 2003, 89, 1085-1092.

198. J. Zeng, X. Xu, X. Chen, Q. Liang, X. Bian, L. Yang and X. Jing: J. Control. Release, 2003, 92, 227-231.

199. Y. Z. Zhang, Z. M. Huang, X. J. Xu, C. T. Lim and S. Ramakrishna: Chem. Mater., 2004, 16, 3406-3409.

200. Y. Z. Zhang, C. T. Lim, S. Ramakrishna and Z. M. Huang: J. Mater. Sci., Mater. Med., 2005, 16, 933-946.

201. Y. Z. Zhang, H. W. Ouyang, C. T. Lim, S. Ramakrishna and Z. M. Huang: J. Biomed. Mater. Res. B, Appl. Biomater., 2005, 72B, $156-165$.

202. S. P. Zhong, W. E. Teo, X. Zhu, R. W. Beuerman, S. Ramakrishna and L. Y. L. Yung: J. Biomed. Mater. Res. A, 2006, 79A, 456-463.

203. X. H. Zong, H. Bien, C. Y. Chung, L. H. Yin, D. F. Fang, B. S. Hsiao, B. Chu and E. Entcheva: Biomaterials, 2005, 26, 5330-5338.

204. X. H. Zong, K. Kim, D. F. Fang, S. F. Ran, B. S. Hsiao and B. Chu: Polymer, 2002, 43, 4403-4412.

205. X. H. Zong, S. Li, E. Chen, B. Garlick, K. S. Kim, D. F. Fang, J. Chiu, T. Zimmerman, C. Brathwaite, B. S. Hsiao and B. Chu: Ann. Surg., 2004, 240, 910-915. 
Copyright of International Materials Reviews is the property of Maney Publishing and its content may not be copied or emailed to multiple sites or posted to a listserv without the copyright holder's express written permission. However, users may print, download, or email articles for individual use. 